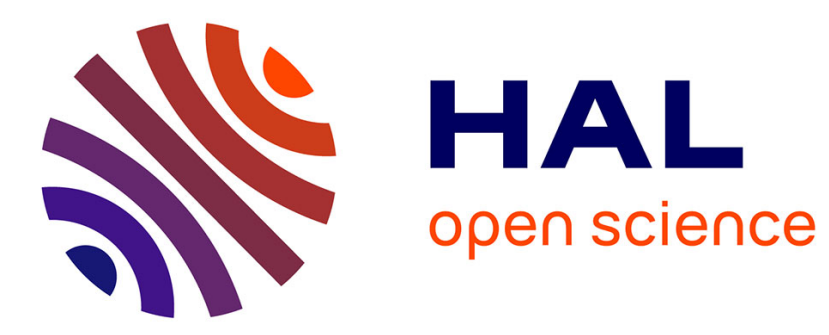

\title{
Evolution of EPDM networks aged by gamma irradiation - Consequences on the mechanical properties
}

Emilie Planes, Laurent Chazeau, Gerard Vigier, Jerome Fournier

\section{To cite this version:}

Emilie Planes, Laurent Chazeau, Gerard Vigier, Jerome Fournier. Evolution of EPDM networks aged by gamma irradiation - Consequences on the mechanical properties. Polymer, 2009, 50 (16), pp.4028-4038. 10.1016/j.polymer.2009.06.036 . hal-00539586

\section{HAL Id: hal-00539586 https://hal.science/hal-00539586}

Submitted on 24 Nov 2010

HAL is a multi-disciplinary open access archive for the deposit and dissemination of scientific research documents, whether they are published or not. The documents may come from teaching and research institutions in France or abroad, or from public or private research centers.
L'archive ouverte pluridisciplinaire HAL, est destinée au dépôt et à la diffusion de documents scientifiques de niveau recherche, publiés ou non, émanant des établissements d'enseignement et de recherche français ou étrangers, des laboratoires publics ou privés. 
Evolution of EPDM networks aged by gamma-irradiation Consequences on the mechanical properties

Emilie PLANES ${ }^{\mathrm{a} b}$, Laurent CHAZEAU $^{\mathrm{a}^{*}}$, Gérard VIGIER $^{\mathrm{a}}$, Jérôme FOURNIER $^{\mathrm{b}}$

a MATEIS, INSA-Lyon, Bâtiment Blaise Pascal, 20 Avenue Albert Einstein, F-69621 Villeurbanne Cedex, France

b NEXANS RESEARCH CENTER, 170 Avenue Jean Jaurès, F-69353 Lyon Cedex 07, France

Graphical abstract:

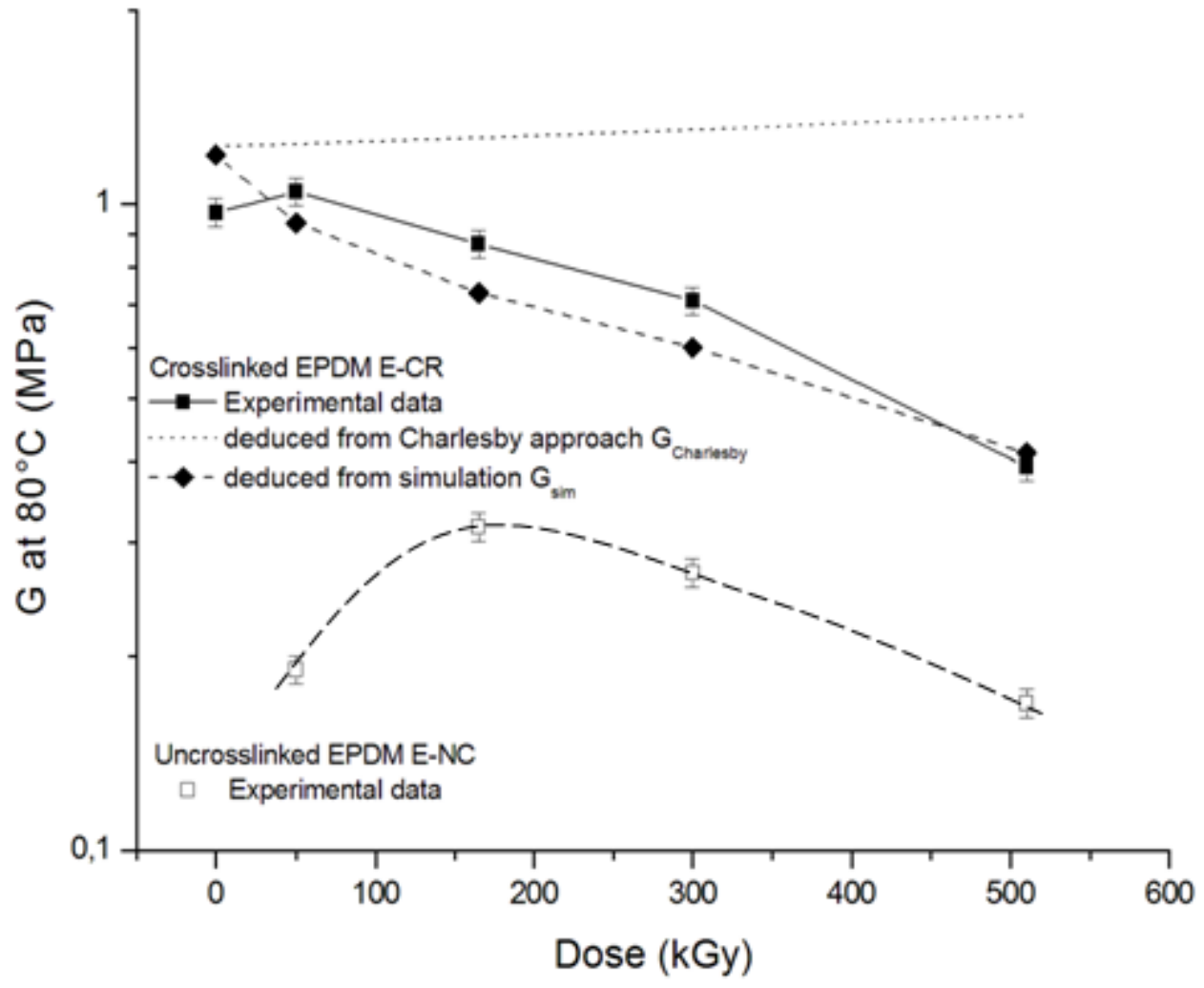

* Corresponding author: Tel : +33472436130; fax : +33472438528.

E-mail address : laurent.chazeau@insa-lyon.fr (L. Chazeau) 
Abstract (142 words):

Different Ethylene Propylene Diene Monomer (EPDM) elastomers with different crosslink densities have been processed in order to evaluate the influence of gamma irradiation on their properties. In the case of a major phenomenon of chain scissions, the consequences are a decrease in the modulus but also a decrease in the strain at break. This decrease in the strain at break is opposite to what is expected for materials with increasing average chain length between crosslinks. To gain more insight into the network architecture, which is presumed to be responsible for this behavior, Charlesby's approach is applied. In tandem, a computational model of the degradation is developed for improved prediction of the evolution of the elastic modulus. Using these calculations, a novel interpretation of the ultimate properties of the elastomer as a function of its architecture is proposed.

Keywords: rubber, irradiation, mechanical properties 


\section{Introduction}

Polymer materials in cables and accessories for nuclear engineering applications must typically be designed to withstand extreme environmental conditions. EPDM is one of the most common polymers for this type of application, used for instance in nuclear power plants. In this kind of application, polymer sheathing may be exposed to elevated temperatures and gamma irradiation which will accelerate its ageing and consequently degrade its useful application lifetime. The study of ageing effects due to gamma irradiation of EPDM elastomers under oxygen atmosphere has led to propose a mechanism of radio-oxidation $[1,2]$. This mechanism artificially induces an accelerated evolution of the mechanical properties material. Indeed, chain scissions occur, counterbalanced by a cross-linking mechanism which depends on the initial cross-linking of the material, which, in turn, leads to modifications of the macroscopic mechanical properties $[3,4,5,6,7]$. The consequence of such ageing, at temperatures higher than the melting temperature of the EPDM crystallites, is a decrease in the material stiffness. Moreover, the presence of crystallites at ambient temperature attenuates this effect $[8,9]$.

Although a qualitative relationship between the macroscopic mechanical properties of the aged samples and the degradation time can easily be proposed, a true understanding of the consequences of degradation of elastomer network structure on its mechanical behavior is much more difficult. This difficulty comes from the fact that there remain several unanswered questions concerning the mechanical behavior of such materials. In particular, the role of network heterogeneities, such as that of crosslink density or the presence of free chains and dangling chains, is still under debate $[10,11,12,13]$. The role of the network imperfections is clearly evident in results from previous modeling efforts presented in the literature to date. One can cite the early work of Termonia $[14,15]$, who studied the network connectivity and 
its mechanical properties, or the work of Grest et al. [16], where particular attention was paid to the influence of strand length, dangling ends and auto-cross-links. Some experimental studies also infer that network imperfections such as free chains reduce the tensile strength and simply result in a "diluted" network [10]. Moreover, the pioneering work of Mark and his collaborators on the effect of the elastomer network architecture stress the importance of the distribution of chain lengths between cross-links in the strength properties of elastomer [11, $12,13]$

Complementing previous experimental study of model elastomers, elastomer degradation by irradiation can provide additional experimental insights into the nature of underlying relationships between network microstructure and mechanical properties (elastic modulus, ultimate properties), since irradiation enables a controlled, progressive manipulation of this microstructure as a function of irradiation dose. Such an approach nonetheless requires a proper understanding of the microstructural evolution of the materials during ageing. Some information on this evolution can be obtained using Charlesby's approach [17,18]. Indeed, this enables to relate crosslinking and scission kinetic to the evolution of the sol fraction. However, the statistical principles behind Charlesby's approach prohibit explicit quantification of network imperfections. The only way to obtain such quantification is to model the network architecture and extract the pertinent parameters describing its real-world behaviour. Recent efforts have therefore been increasingly devoted to modeling the molecular dynamics of the formation of polymer networks via the cross-linking process. Among them, one can cite the recent work of Rottach $[19,20,21]$ who extended his research to the crosslinking process of network during stretching. Though of obvious interest, this type of model is difficult to directly apply to the case of any particular experimental study. In the specific case of irradiation, it can in fact be more revealing to use a simpler description of the network 
architecture based on experimental data, in order to expose the direct relationship between mechanical properties of materials and their exposure to radiation.

Thus, in this work, different EPDM networks are elaborated: pure gum (non-crosslinked EPDM) and EPDM crosslinked by peroxide, both aged by gamma irradiation at room temperature under oxygen atmosphere, and EPDM crosslinked by peroxide at various degrees. Note that, given the semi-crystalline nature of the EPDM at room temperature [9], the work described in the article concerns EPDM at $80^{\circ} \mathrm{C}$, i.e. above its melting temperature. The materials are tested by mechanical test, swelling behavior and thermoporosimetry. In addition, a modeling of the network architecture is presented, which enables a description of evolution in relation with the experimental data. Our results lead us to conclude that irradiation causes significant defects in the network structure. The level of defects is in fact so high in rubber materials that their mechanical properties can in fact no longer be correlated at all with the standard measures of crosslink density or length of chain between cross-links.

\section{Experimental}

\subsection{Materials}

The EPDM elastomer (Nordel IP NDR 3722 P from Dow Chemical Company) is composed of $70 \%$ ethylene, $29.5 \%$ propylene and $0.5 \%$ ENB. An analysis by gel permeation chromatography (GPC) gives the following results:

$\overline{M_{w}}=39300 \mathrm{~g} / \mathrm{mol}, \overline{M_{n}}=5140 \mathrm{~g} / \mathrm{mol}$.

EPDM plates $(1 \mathrm{~mm})$ are produced with two formulations: pure gum (E-NC) and crosslinked elastomer (E-CR). 
The samples are processed following three steps. The first step involves mixing the matrix and introducing a crosslinking agent to the polymer. Specifically, after 5 minutes of mixing in an internal mixer, peroxide is added. Its dispersion is permitted for $10 \mathrm{~min}$ at low temperature $\left(80^{\circ} \mathrm{C}\right)$ to prevent any reaction of the cross-linking system. In order to obtain a better dispersion, the second step is mixing in an external mixer (cylinders) for $10 \mathrm{~min}$ at low temperature $\left(80^{\circ} \mathrm{C}\right)$. During the last step, the compound is pressed over a 10 -minute period into 1 -mm-thick films at $170{ }^{\circ} \mathrm{C}$, in order to promote a cross-linking reaction. The crosslinking agent we used is the dicumyl peroxide (Perkadox BC-FF from Akzo Nobel), introduced at $3 \mathrm{phr}$. The curing time $\left(\mathrm{t}_{98}\right.$ at $\left.170^{\circ} \mathrm{C}\right)$ is determined from torque measurements performed with a MOSANTO analyzer. During curing of ethylene-propylene elastomer [22], the peroxide decomposes into radicals at elevated temperature, which results in the formation of peroxy radicals. They can react with the polymer chains by abstraction of hydrogen atoms to produce macroradicals. Two types of chemical cross-links are formed, one type via combination of peroxide-induced EPDM macroradicals and the other one via addition of the macroradicals to the residual double bonds of the termonomer. Actually, peroxide cure of EPM (without termonomer) is relatively inefficient. This is mainly due to scission reactions occurring on tertiary radicals created by $\mathrm{H}$-abstraction in the propylene sequence. Moreover a total efficiency of peroxide is usually inhibited by occurrence of all kinds of auxiliary reactions, such as alternative peroxide decomposition pathways leading to inert products, combination of peroxide-derived radicals and/or disproportionation of radicals.

Two elastomers with smaller crosslinking degrees are produced as a final result, by choosing different curing times: 2min, 3min. They will be called E-CR2min and E-CR3min (see Table 1). As the soluble fraction in all crosslinked samples is zero, we can assume that all chains are 
crosslinked. The samples are then artificially exposed to gamma radiation as described below.

\begin{tabular}{|c|c|c|c|c|}
\hline & EPDM & Peroxide & $\begin{array}{c}\text { Curing Time } \\
(\mathrm{min})\end{array}$ & $\mathrm{F}_{5}(\%)$ \\
\hline E-NC & 100 & - & - & 100 \\
\hline E-CR & 100 & 3 & 10 & 0 \\
\hline E-CR3min & 100 & 3 & 3 & 0 \\
\hline E-CR2min & 100 & 3 & 2 & 0 \\
\hline
\end{tabular}

Table 1: Composition and swelling data of the studied materials (The proportions are expressed in phr: per hundred parts of matrix)

\subsection{Ageing conditions}

E-NC and E-CR are exposed to $\gamma$-radiation of a ${ }^{60} \mathrm{CO}$ source at a dose rate of $1 \mathrm{kGy} / \mathrm{h}$ at room temperature in an oxygen atmosphere for doses 50, 165, 300, $510 \mathrm{kGy}$ (Arc Nucleart Grenoble France). The samples are stored under vacuum at room temperature.

Radio-oxidation of EPDM macromolecules leads to the observation by IR spectroscopy of an increase in absorbance in the hydroxyl absorption region $\left(3800-3000 \mathrm{~cm}^{-1}\right)$ [1,2] corresponding to the formation of alcohols, acids and hydroperoxides. The formation of carbonyls can also be evidenced by the absorption maximum at $1713 \mathrm{~cm}^{-1}$ with several shoulders around 1785, 1755, 1740, and $1695 \mathrm{~cm}^{-1}[1]$. Analysis of the oxidation product distributions within the oxidized E-CR is made for E-CR-510, and the variations in absorbance at $1713 \mathrm{~cm}^{-1}$ are chosen to characterize the product distributions according to thickness. The oxidation profile is found flat for this dose, which indicates that, in these 
conditions of irradiation, the oxidation processes are homogeneously distributed within the sample. The samples will be named hereafter E-CR-XXX and E-NC-XXX with XXX denoting the radiation dose.

\subsection{Instruments}

\subsubsection{Swelling measurements}

Samples with an initial mass $\mathrm{M}_{\mathrm{i}}$ are introduced into a xylene composition over an 8-day period to permit them to achieve swelling equilibrium. Then the materials with swelled mass $\mathrm{M}_{\mathrm{s}}$ are dried under vacuum at $60^{\circ} \mathrm{C}$ for 24 hours and weighted in order to obtain their dry mass $\mathrm{M}_{\mathrm{d}}$. The soluble fraction $\mathrm{F}_{\mathrm{s}}$ and the swelling ratio $\mathrm{Q}$ are calculated from the following relations:

$$
\begin{gathered}
F_{s}=1-\frac{M_{d}}{M_{i}} \quad(1) \\
Q=1+\frac{\rho_{\text {polymer }}}{\rho_{\text {xylene }}} \frac{M_{s}-M_{d}}{M_{d}}
\end{gathered}
$$

Matrix network chain density in the swollen materials can be estimated from swelling ratio in xylene Q using the Flory-Rehner equation [23]. This equation depends on the network functionality f (non-aged crosslinked samples have a functionality 4), and $\chi_{1}$ the FloryHuggins polymer-solvent dimensionless interaction term. It is noteworthy that the functionality $\mathrm{f}$ is decreased as a result of material ageing. More importantly, the value of the Flory Huggins parameter is difficult to estimate, especially after material degradation, since the polarity of the chemical composition can be strongly affected. Moreover, the result calculated from the Flory-Rehner equation is strongly sensitive to this value. These two observations suggest considering with caution the crosslink density values deduced using this technique. Therefore, we will only consider the swelling ratio and the sol fraction as reliable 
data. We are supported in this choice by the recent paper of Valentin et al. [24] who clearly demonstrate the uncertainties in the determination of elastomer network characterized by swelling technique.

\subsubsection{Tensile tests}

Tensile tests are performed on an MTS device with a temperature-controlled chamber. An image processing acquisition system (Apollor VideoTraction System) is used to obtain the true stress-strain curve. Experiments are carried out at $80^{\circ} \mathrm{C}$ (above the melting temperature) with a $0.01 \mathrm{~s}^{-1}$ true strain rate. The samples are dumbbell-shaped with typical dimensions $20 \mathrm{x}$ $4 \times 1 \mathrm{~mm}^{3}$. For each material, three specimens are tested. In the figures shown only one test is reported, but the average stress and strain at break of the three specimens, with error bars, is given in figure 8.

The elastic modulus $\mathrm{E}$ is calculated as the slope at the origin of the true strain - true stress curve. The shear modulus $\mathrm{G}$ is deduced from the tensile elastic modulus $\mathrm{E}$, assuming that the material, like any rubber, is quasi-incompressible: The Poisson coefficient is therefore approximated to 0.5 .

\subsubsection{Thermoporosimetry}

One way of quantifying the heterogeneity of an elastomer network is by observation of the melting or freezing point of adsorbed solvent within the elastomer network. This technique is generally called thermoporosimetry. This experiment is based on the fact that solvent molecules constrained to small volumes form only relatively small crystallites upon crystallization and therefore exhibit lower crystallization temperatures [25]. Broad distributions of cavity sizes should give rise to broad distributions of crystallites sizes and thus crystallites melting points [26]. Therefore, differential scanning calorimetry 
measurements performed on swollen sample with solvent molecules constrained in the pores can give evidence of several crystallization temperatures, which are indicative of the pore sizes and of the distributions of these sizes.

The samples are therefore swollen in cyclohexane. Then they are carefully extracted and put into an aluminum crucible fully filled with the same solvent. The melting behavior of the solvent in the samples is studied using a Perkin-Elmer Pyris Diamond differential scanning calorimeter (DSC). The temperature and heat flow of the DSC are calibrated using a standard reference (Indium). A cooling scan is first run at $10^{\circ} \mathrm{C} / \mathrm{min}$ from room temperature to $-50^{\circ} \mathrm{C}$ and the instrument held isothermally at $-50^{\circ} \mathrm{C}$ for $2 \mathrm{~min}$. This is followed by a heating scan at $10^{\circ} \mathrm{C} / \mathrm{min}$ up to $+40^{\circ} \mathrm{C}$. While increasing temperature from $-50^{\circ} \mathrm{C}$ to $+40^{\circ} \mathrm{C}$, a first peak appears for swollen network which corresponds to the melting of the cyclohexane entrapped in the network. Then a second strong peak corresponding to the melting point of the free cyclohexane (in excess) is visible at around $0^{\circ} \mathrm{C}$. We will return to the analysis procedure of the experimental results later in this article.

\section{Results}

\subsection{Degradation kinetic}

The evolutions of $\mathrm{Q}$ and of soluble fraction $\mathrm{F}_{\mathrm{s}}$ with the irradiation dose for E-CR are shown in figure 1a). Between 0 and $50 \mathrm{kGy}$, we can only note a little evolution of $\mathrm{F}_{\mathrm{s}}$ while $\mathrm{Q}$ remains constant. This means that chain scissions and crosslinking are in competition. After $50 \mathrm{kGy}$, chain scissions seem to be the most important phenomenon: Q rapidly increases with the irradiation dose as well the soluble fraction $\mathrm{F}_{\mathrm{s}}$. The evolutions of $\mathrm{Q}$ and $\mathrm{F}_{\mathrm{s}}$ with the irradiation dose for E-NC are also shown on the figure $1 b) . F_{s}$ decreases with irradiation dose, then stabilizes and begins to increase at $510 \mathrm{kGy}$. Q follows the same evolution. Between 0 and 
$300 \mathrm{kGy}$, the major phenomenon is crosslinking while at higher doses the main occurring process is chain scission. The minimum $Q$ value $(Q=25)$ is still large compared to the initial $\mathrm{Q}$ value of unaged E-CR (at $0 \mathrm{kGy}, \mathrm{Q}=3.7$ ). This means that the cross-linking process of $\mathrm{E}$ NC by irradiation is rapidly counterbalanced by chain scissions.

These results are in agreement with the evolution of the experimental elasticity moduli of E$\mathrm{NC}$ and E-CR as a function of the irradiation dose, which are presented in Figure 2. The major chain scission phenomenon occurring under irradiation is evidenced for E-CR as a rapid decrease in the modulus of elasticity. The modulus slightly increases at the first dose (50kGy), confirming the occurrence of an initial cross-linking. In the case of E-NC, first an increase in the modulus is observed, significant of a major cross-linking phenomenon. Then above 165 $\mathrm{kGy}$, chain scissions mainly take place as evidenced by the modulus decrease. 

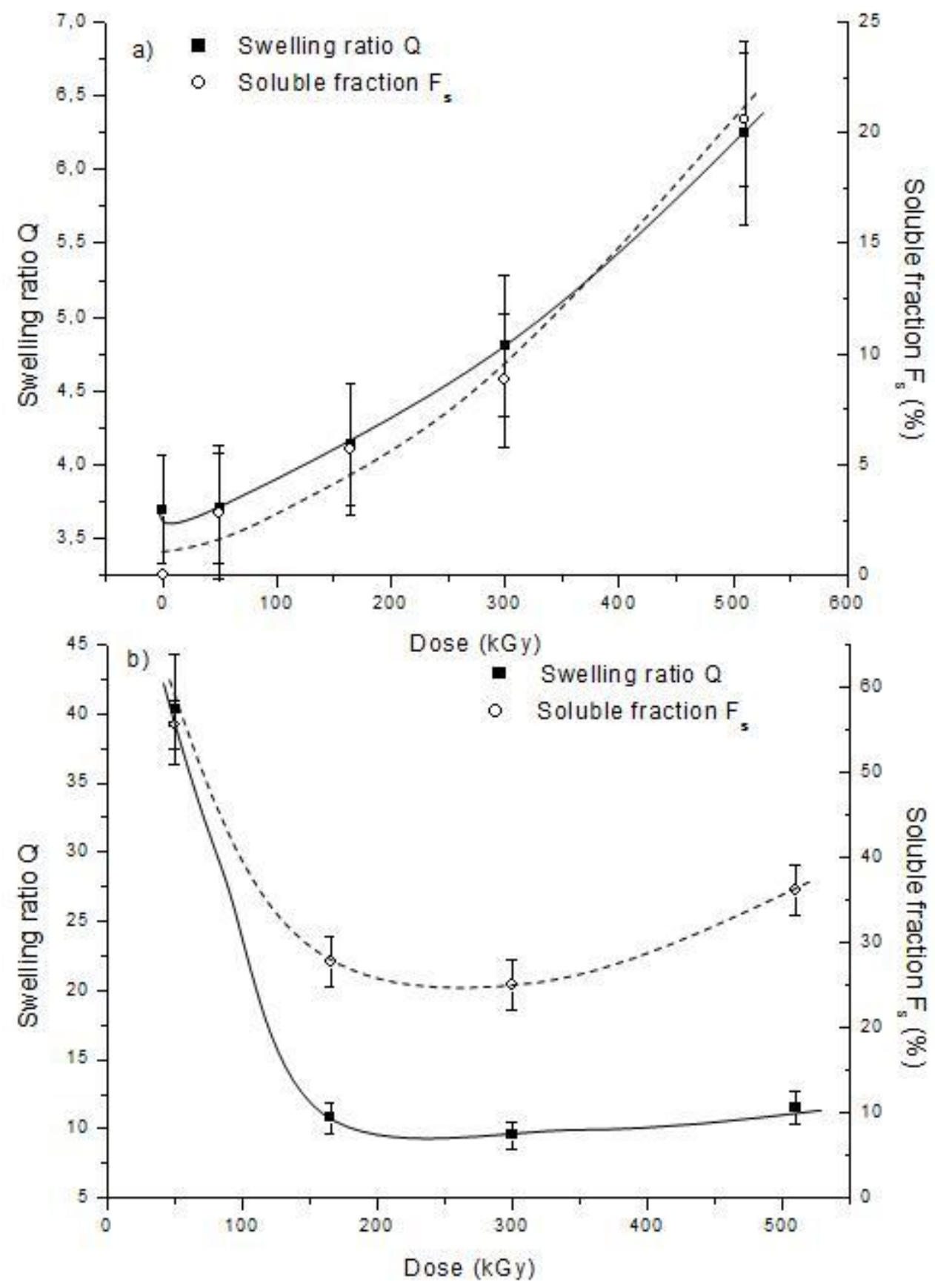

Figure 1: Evolution of the swelling ratio $Q$ and the soluble fraction $F_{s}$ with an increasing irradiation dose for a) E-CR and for b) E-NC (Continuous and dashed lines are guidelines) 


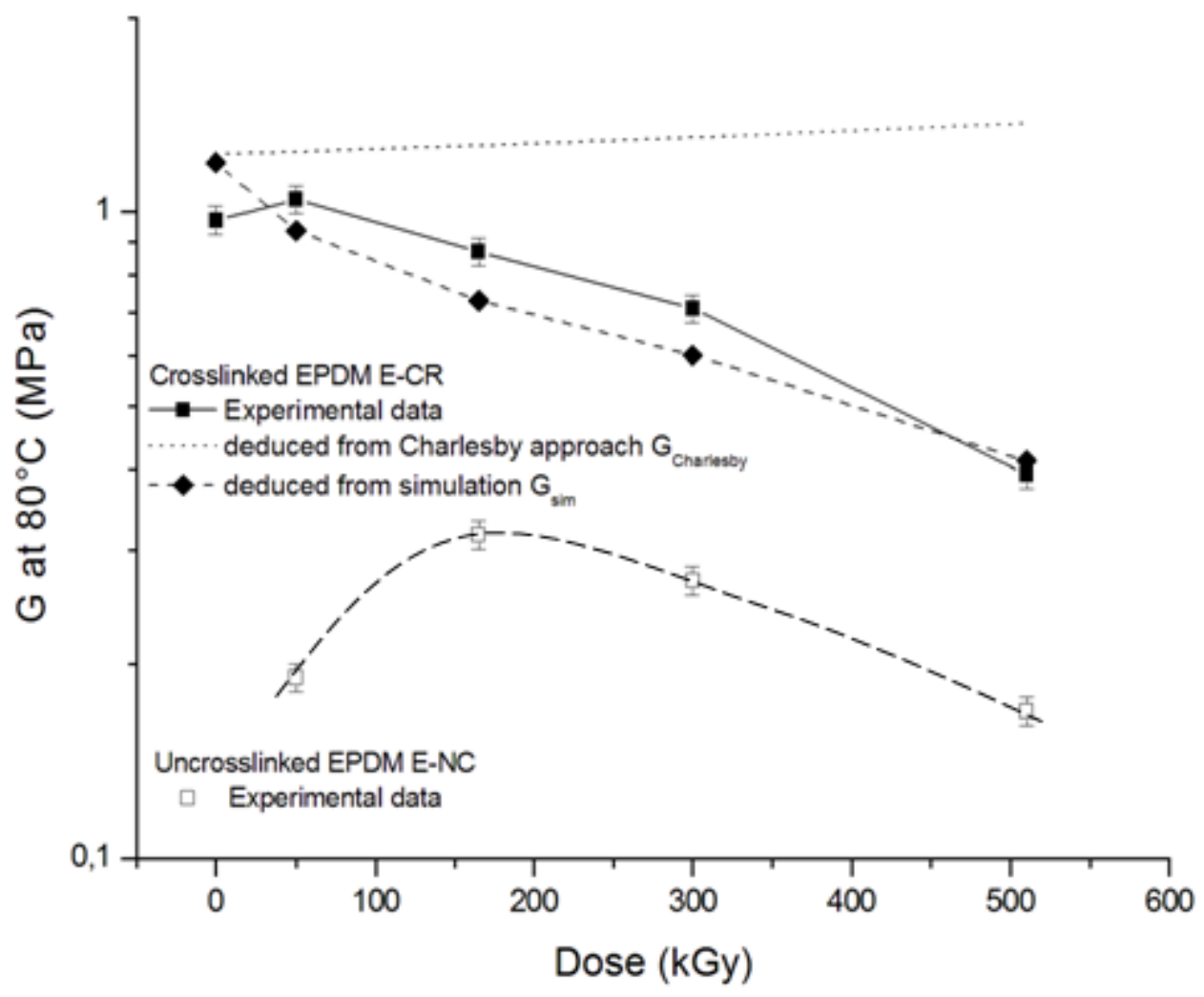

Figure 2: Evolution of the shear modulus $\mathrm{G}$ at $80^{\circ} \mathrm{C}$ with an increasing irradiation dose for E-NC and for E-CR.

Using affine network theory, the active chains concentration $v_{c}$ can be deduced from the modulus G, following the equation [23]:

$$
v_{c}=\frac{G}{R T}\left(1-F_{s}\right)^{-1 / 3}
$$

Figure 3 presents the evolution of deduced active chain concentration of E-CR sample. As chain scissions dominate beyond $50 \mathrm{kGy}$, and in order to estimate the chain scission kinetic action independent of the cross-linking process, we have chosen to fit the experimental $v_{\mathrm{c}}$ data by an exponential decay law at radiation doses above $50 \mathrm{kGy}$ : 


$$
v_{c}=v_{0} \exp \left(\frac{-G_{s}}{n_{0}} D\right)
$$

where $\mathrm{D}$ is the radiation dose.

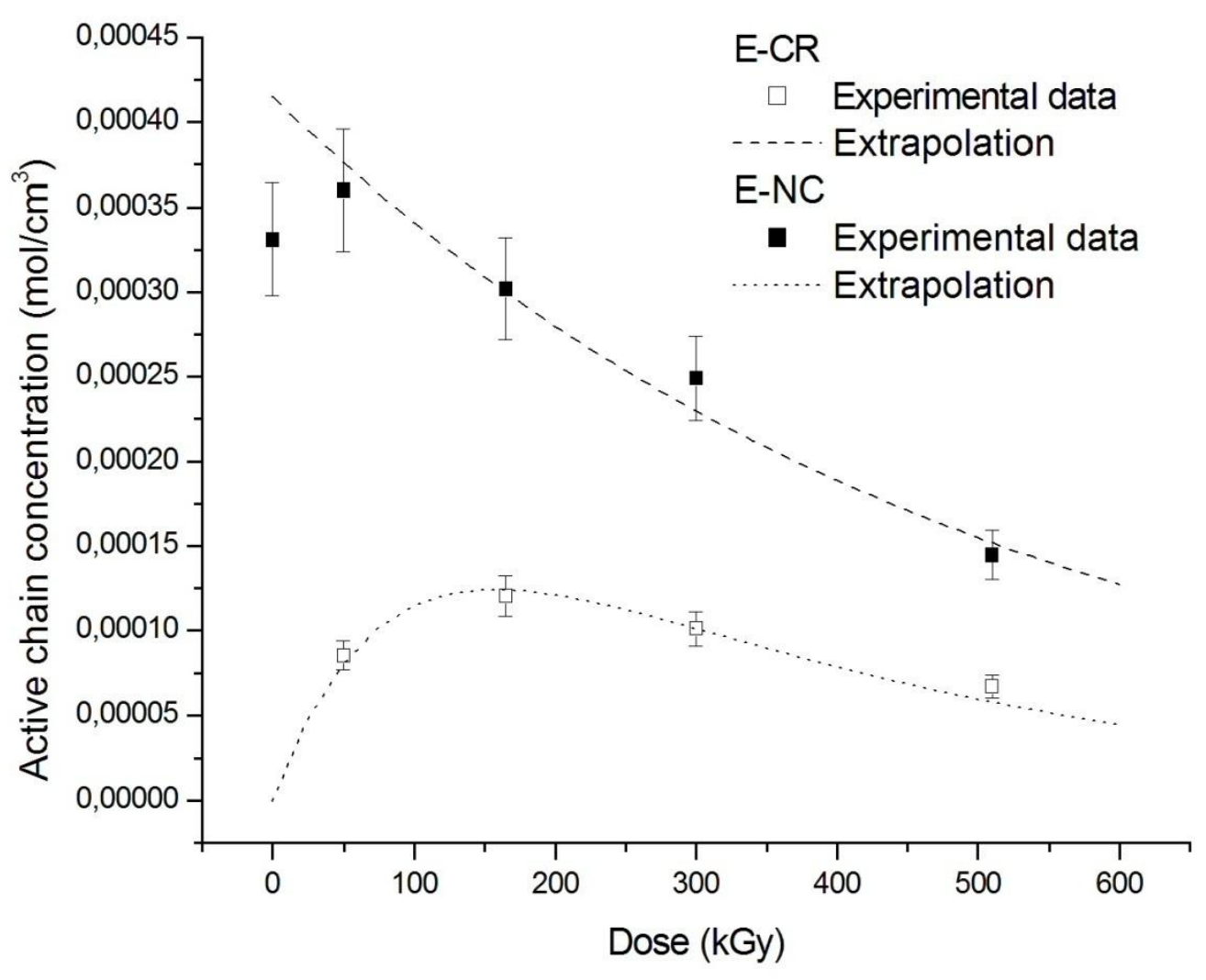

Figure 3: Evolution of the apparent crosslink density versus irradiation dose with the phenomenological fits for E-CR and E-NC

Note that for small radiation doses, this law can be approximated as:

$$
v_{c}=v_{0}-G_{s} D
$$

with $v_{0}$ the initial active chain density and $G_{s}$ the chain scission yield (mol/J) of the chains belonging to the network. The parameters deduced from the fit are: $v_{0}=4.15 \times 10^{-4} \mathrm{~mol} / \mathrm{cm}^{3}$ and $\mathrm{G}_{\mathrm{s}}=8.1 \times 10^{-7} \mathrm{~mol} / \mathrm{J}$. Kelidj et al.[27] have estimated from their kinetic model a chain 
scission yield for two polyethylenes studied by Decker et al.[28] irradiated at 0.292 Gy.s ${ }^{-1}$ $\left(1.05 \mathrm{kGy} \cdot \mathrm{h}^{-1}\right)$ with different crystallinity ratios: $50 \%$ and $75 \%$. The values are respectively $3.3 \times 10^{-7} \mathrm{~mol} / \mathrm{J}$ and $2.6 \times 10^{-7} \mathrm{~mol} / \mathrm{J}$. They can be compared to the $\mathrm{G}_{\mathrm{s}}$ value deduced from our fit. In our case, the chain scission yield is higher. This difference could be explained by the lower crystallinity of our samples compared to that in the previous studies. Indeed, in the crystalline regions the macromolecules have very small mobility and the oxygen is almost unable to diffuse; diffusion constants for crystalline phase are small, around 8 or 9 orders of magnitude smaller than in the amorphous region. For that reason, chain scissions mostly take place in the amorphous regions. Taking into account the crystallinity of our materials (around 11\%), our chain scission yield related to the amorphous part $\left(9.1 \times 10^{-7} \mathrm{~mol} / \mathrm{J}\right)$ is between the values deduced from the Decker data $\left(6.6 \times 10^{-7} \mathrm{~mol} / \mathrm{J}\right.$ and $10.4 \times 10^{-7} \mathrm{~mol} / \mathrm{J}$ respectively). An alternative explanation is as follows: The studied rubber is a copolymer with a non-negligible fraction of propylene and this termonomer is more sensitive to chain scissions [29]. The $v_{0}$ value deduced from our fit can be seen as the assumed initial crosslink density value of an E-CR that would have given the experimental cross-linking density evolution as a function of the irradiation dose, if only the chain scission processes had taken place. Such value corresponds to a molar mass between cross-links of $2200 \mathrm{~g} / \mathrm{mol}$ (calculation made with an EPDM density of 0.9).

Figure 3 also presents the apparent cross-linked density of E-NC deduced from equation (3), as a function of the irradiation dose. In this case, the cross-linking process is significant and precludes a similar curve fit. However, the material degradation can be seen as the successive occurrence of a cross-linking process, which leads to a material with a given crosslink density, submitted afterwards to a degradation process similar to that occurring in the E-CR sample. The cross-linking process is assumed to be governed by the gap between the actual cross-link density $v_{0}$ ' and an equilibrium cross-link density $v_{0 \text { eq. }}$. This can be empirically modeled by the formula: 


$$
v_{0}^{\prime}=v_{0 e q}\left(1-\exp \left(\frac{-2 G_{c}}{v_{o e q}} D\right)\right)
$$

with $G_{c}$ the cross-linking yield (proportion of cross-linked monomer units per energy unit). The factor of two in the exponential represents the fact that one cross-link induces two monomer units.

From this the assumption can be made that the scission kinetic is the same as for E-CR. Under this assumption, the apparent active chain density $v_{\mathrm{c}}$ of E-NC is:

$$
v_{c}=v_{0} \exp \left(\frac{-G_{s} D}{v_{0 e q}}\right)=v_{0 e q}\left(1-\exp \left(\frac{-2 G_{c} D}{v_{0 e q}}\right)\right) \exp \left(\frac{-G_{s} D}{v_{0 e q}}\right)
$$

The corresponding fit is very satisfactory and is presented on figure 3 . The parameters deduced from the fit are $v_{0 \text { eq }}=2.7 \times 10^{-4} \mathrm{~mol} / \mathrm{cm}^{3}$, which is assumed to be constant, and $\mathrm{G}_{\mathrm{c}}=$ $1.15 \times 10^{-6} \mathrm{~mol} / \mathrm{J}$. The maximal active chain density obtained by peroxide cure, and deduced from E-CR was previously found to be $4.15 \times 10^{-4} \mathrm{~mol} / \mathrm{cm}^{3}$. Both values are of the same order. Thus, within the assumption of this phenomenological model, the number of cross-linking sites potentially activated by gamma-irradiation is on the same order as that generated by peroxide cross-linking. Note that this phenomenological approach implicitly makes the strong assumption that the cross-linking process involved during the degradation mechanism would lead, without the concomitant occurrence of chain scissions, to a cross-linking of the network without any sol fraction (since otherwise one must account for the possible scission of chains of the sol fraction).

To gain further insight into the kinetic degradation of the E-CR material, the CharlesbyPinner approach is used [14]. It provides a simple expression relating sol fraction $F_{s}$ to 
irradiation dose $\mathrm{D}$, in the specific case of an initial random distribution of the molar weight of the polymer chains under the assumption that cross-linking and scission occur at random.

$$
F_{s}+\sqrt{F_{s}}=\frac{p(D)}{q(D)}+\frac{1}{q(D) u_{1}}
$$

Where $D$ is the irradiation dose, $q(D)$ is the proportion of cross-linked monomer unit and $p(D)$ is the number of chain scissions per monomer unit. The parameter $\mathrm{u}_{1}$ is related to the initial distribution:

$$
u_{1}=\overline{M_{n}} / w
$$

With $\overline{M_{n}}$ and w the average number molar weight and the molar mass of the polymer unit.

The relation (8) holds whether or not main-chain fracture occurs simultaneously with crosslinking. Indeed this relation allows one to consider a material undergoing simultaneous crosslinking and scission as it first experienced scission, only then followed by cross-linking. This relation is only valid in the case of an initial random distribution. For other distributions, there is no analytical expression. The relation remains valid, however, for large numbers of scissions, since the initial distribution tends to be a random after a large number of scissions. 


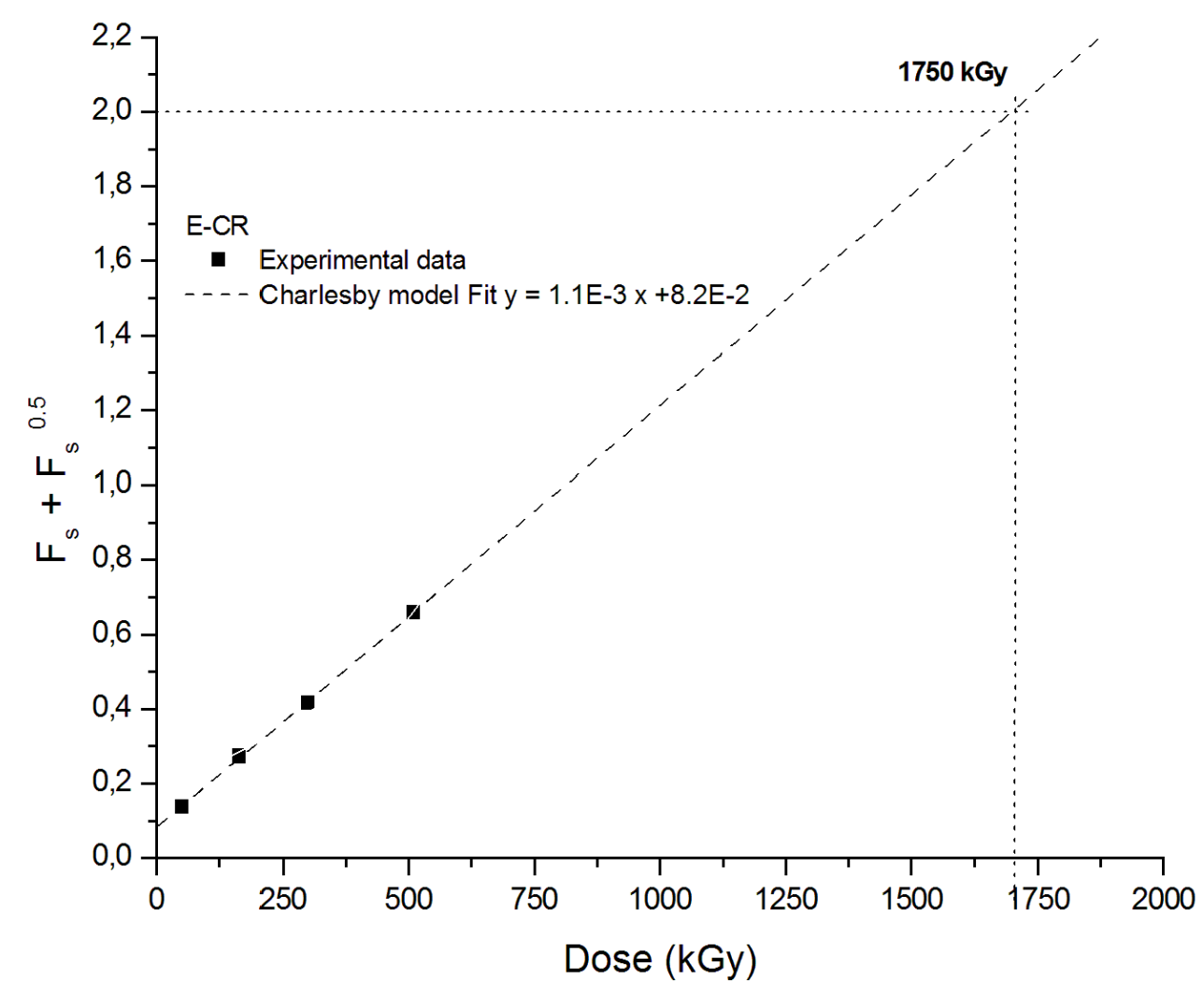

Figure 4: Evolution of $F_{s}+\sqrt{F_{s}}$ versus irradiation dose, compared with relation (8)

In our study, as shown previously, the E-CR material is submitted to a competition of the phenomena of cross-linking and chain scissions between 0 and $50 \mathrm{kGy}$. After $50 \mathrm{kGy}$, the major phenomenon is scissions. Thus the proportion of cross-linked monomer $q(D)$ is taken independent on $\mathrm{D}$, as a constant $\mathrm{q}_{\mathrm{f}}$. The value of this constant can be estimated from the elastic modulus data. The average molar mass between cross-links of the modeled E-CR is estimated equal to $2200 \mathrm{~g} / \mathrm{mol}$ through the previous extrapolation at $0 \mathrm{kGy}$ of the active chain concentration (cf. figure 3). This is equivalent to considering an initial average chain length between cross-links $N_{c}$ of 66 units (calculation made with an EPDM unit with a molar mass of $32.6 \mathrm{~g} / \mathrm{mol}$ ). We can also make the assumption (as Charlesby did) that $\mathrm{q}(\mathrm{D})$ is proportional to irradiation dose. 
Thus the relation (8) becomes affine in D:

$$
F_{s}+\sqrt{F_{s}}=\frac{p_{0} D}{q_{f}}+\frac{1}{q_{f} u_{1}}
$$

with $\mathrm{p}_{0}$ a constant. As shown in the figure 4 , the experimental evolution of $F_{s}+\sqrt{F_{s}}$ versus irradiation dose is in good agreement with the relation (10). Taking for $p_{0} / q_{f}$ a value of $1.1 \times 10^{-3} \mathrm{kGy}^{-1}$, a chain scission yield $\mathrm{G}_{\mathrm{s}-\text { charlesby }}$ can be deduced: It is found that $5.2 \times 10^{-7} \mathrm{~mol} / \mathrm{J}$ is in good agreement with the previous value $\mathrm{G}_{\mathrm{s}}\left(8.1 \times 10^{-7} \mathrm{~mol} / \mathrm{J}\right)$. This value is also in agreement with the work of Decker et al. [28] taking in account the crystallinity ratio. The number of scissions per monomer unit as a function of the irradiation dose calculated using the deduced $\mathrm{p}_{0}$ value is presented in figure 5 .

Returning to figure 4 , we note that the intercept point of the affine fit is $8.2 \times 10^{-2}$. Within the assumption of an initially random distribution of the polymer, an average number molar weight of the unlinked polymer can be estimated to be approximately $26000 \mathrm{~g} / \mathrm{mol}$. This value is larger than that of our polymer $\left(\overline{M_{n}}=5140 \mathrm{~g} / \mathrm{mol}\right)$, but this discrepancy could be explained by the fact that the initial molar weight distribution of the polymer is not random, in other words that the equation (10) is not valid for low radiation doses. From the same fit of figure 4 , we can also calculate the irradiation dose required to reach the complete degradation of the polymer, that is, when the soluble fraction is equal to 1 . The extrapolated value is 1750 kGy. 


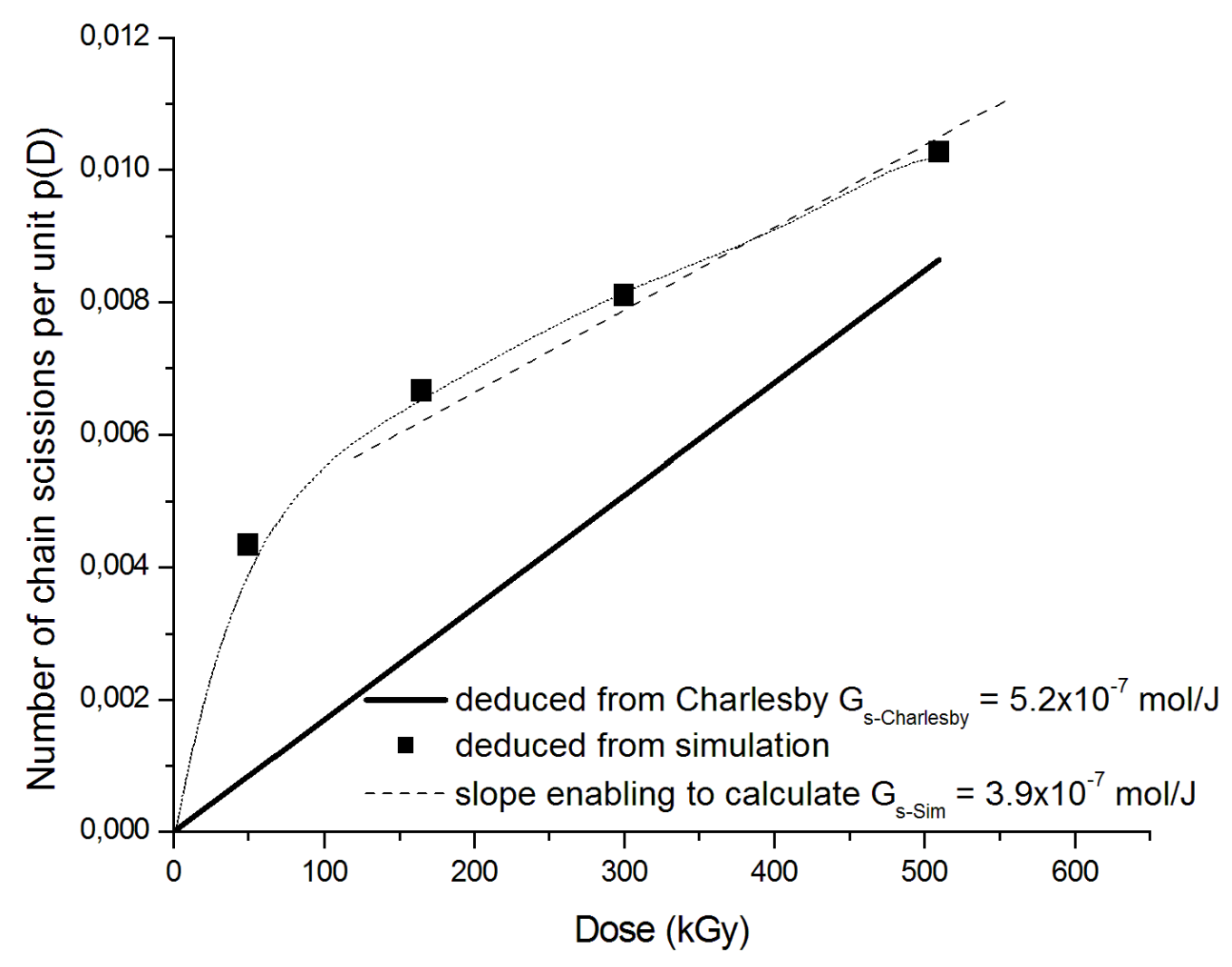

Figure 5: Number of chain scissions as a function of the irradiation dose $p(D)$, deduced from Charlesby and from the simulation and the experimental soluble fractions for E-CR

Charlesby [15] also proposed a relationship between the average weight between cross-links $\mathrm{M}_{\mathrm{c}}$ in the gel, the sol fraction and the cross-link density:

$$
M_{c}=\frac{w}{q\left(1+F_{s}\right)}
$$

From this relation and the work of Flory [23], it is possible to derive the shear modulus $\mathrm{G}_{\text {Charlesby }}$ of the E-CR material:

$$
G_{\text {Charlesby }}=\frac{\rho R T\left(1-F_{s}\right)^{1 / 3}}{M_{c}}
$$


As shown in figure 2, equation (12) does not describe properly the evolution of the shear modulus of E-CR. Ergo, while Charlesby's approach is very convincing for the description of the sol fraction evolution, its $\mathrm{M}_{\mathrm{c}}$ calculation cannot aid in predicting the modulus. This is not unexpected since equations (11)-(12) do not take in account the irregularities of the network provoked by the chain scission process. The sol fraction used in equation (12) is not entirely representative of the inactive chains, because the dangling chains do not take part in the network mechanical properties (if entanglement effects are neglected). Moreover the average molar weight between active cross-links $\mathbf{M}_{c}$ is underestimated: Active chains may include inactive cross-links, therefore their effective length should be calculated from the length between active cross-links alone. (Note that the increase predicted by Charlesby is due to the fact that chain scissions first occur in the longest chains which automatically lead to a decrease in $\mathbf{M}_{\mathrm{c}}$.) An accurate prediction of the modulus must include consideration of these aspects.

\subsection{Large strain behavior}

Consequences of irradiation on the mechanical behavior of E-NC and E-CR at large strain are presented on figures 6,7 , and 8 respectively. In agreement with results previously obtained with E-NC (from 0 to $165 \mathrm{kGy}$ ), the stress level for a given strain increases. This confirms that the predominant phenomenon taking place is in fact cross-linking. Subsequently, from $165 \mathrm{kGy}$ to $510 \mathrm{kGy}$, chain scissions predominate, resulting in a decrease in the stress level. Note that the non irradiated E-NC flows in the clamps. This was expected since the testing temperature is much higher than the glass transition temperature of the polymer. This indicates that the entanglements contribution to the stiffness of the irradiated materials can be 
neglected at $80^{\circ} \mathrm{C}$. Concerning the rupture behavior, the formation of cross-links and chain scissions under irradiation does not significantly influence the elongation at break, though the evolution of the stress at break follows the same trend as the evolution of the elastic modulus.

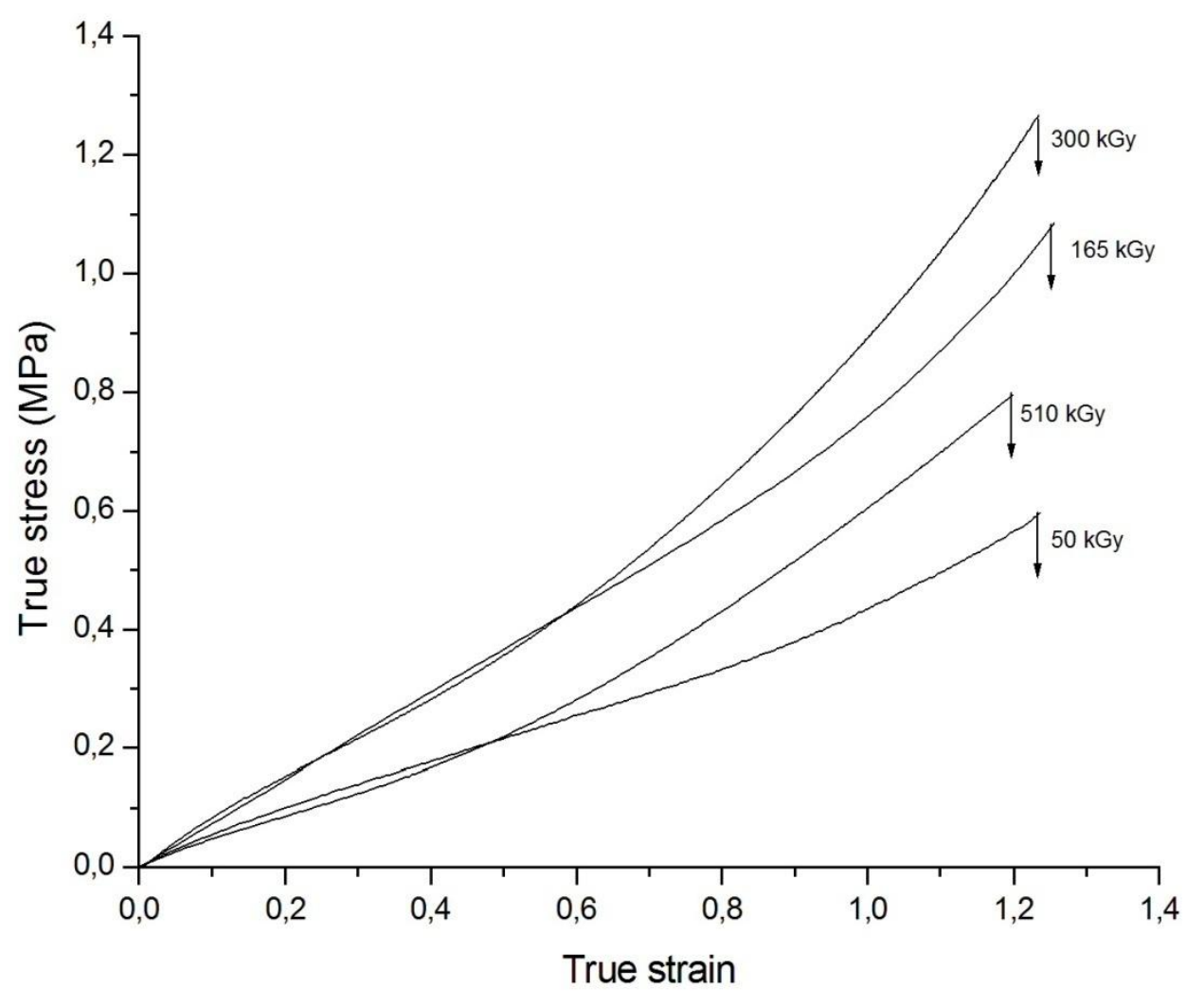

Figure 6: Large deformation behaviors at $80^{\circ} \mathrm{C}$ of $\mathrm{E}-\mathrm{NC}$ 


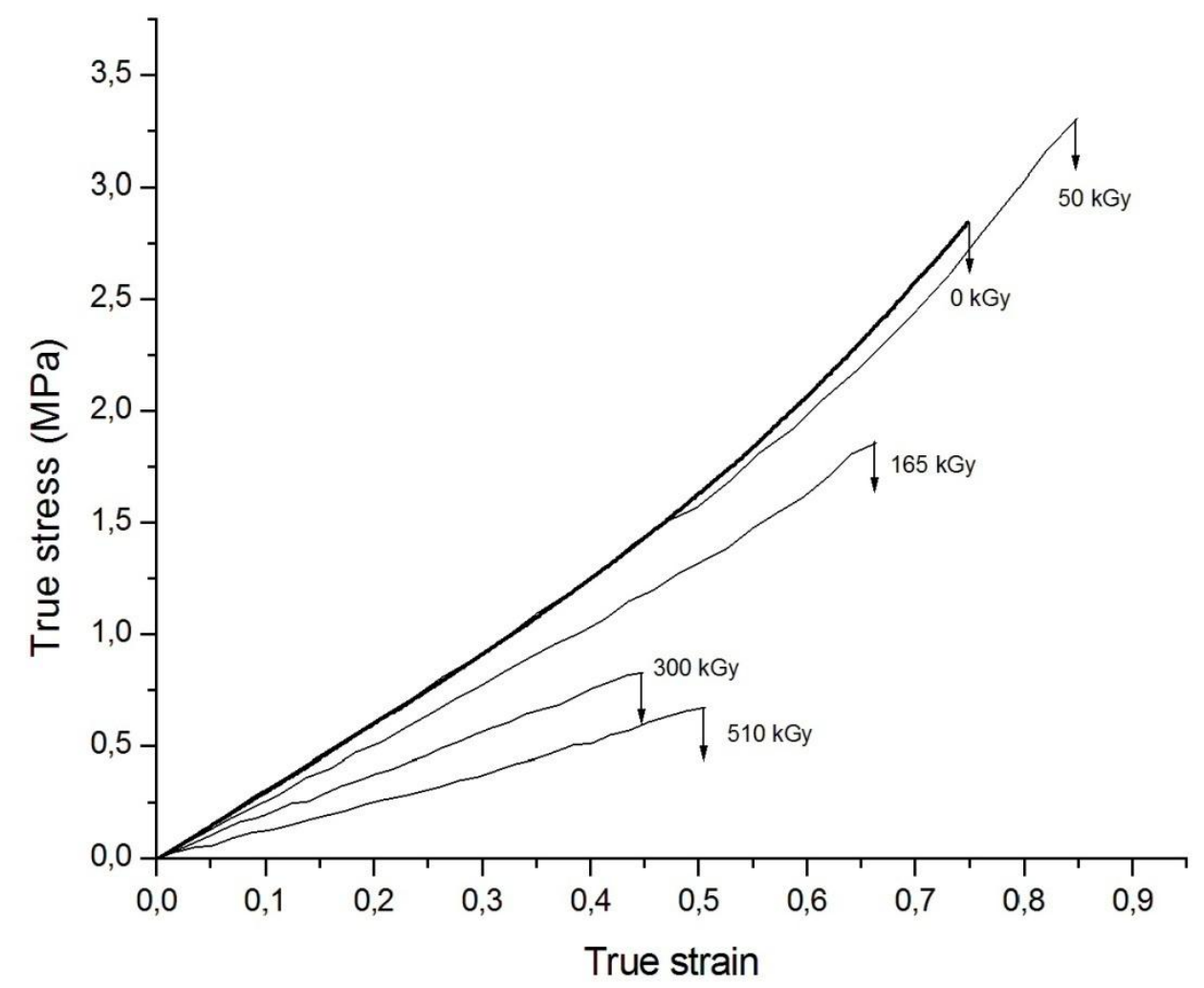

Figure 7: Large strain behaviors at $80^{\circ} \mathrm{C}$ of $\mathrm{E}-\mathrm{CR}$ 

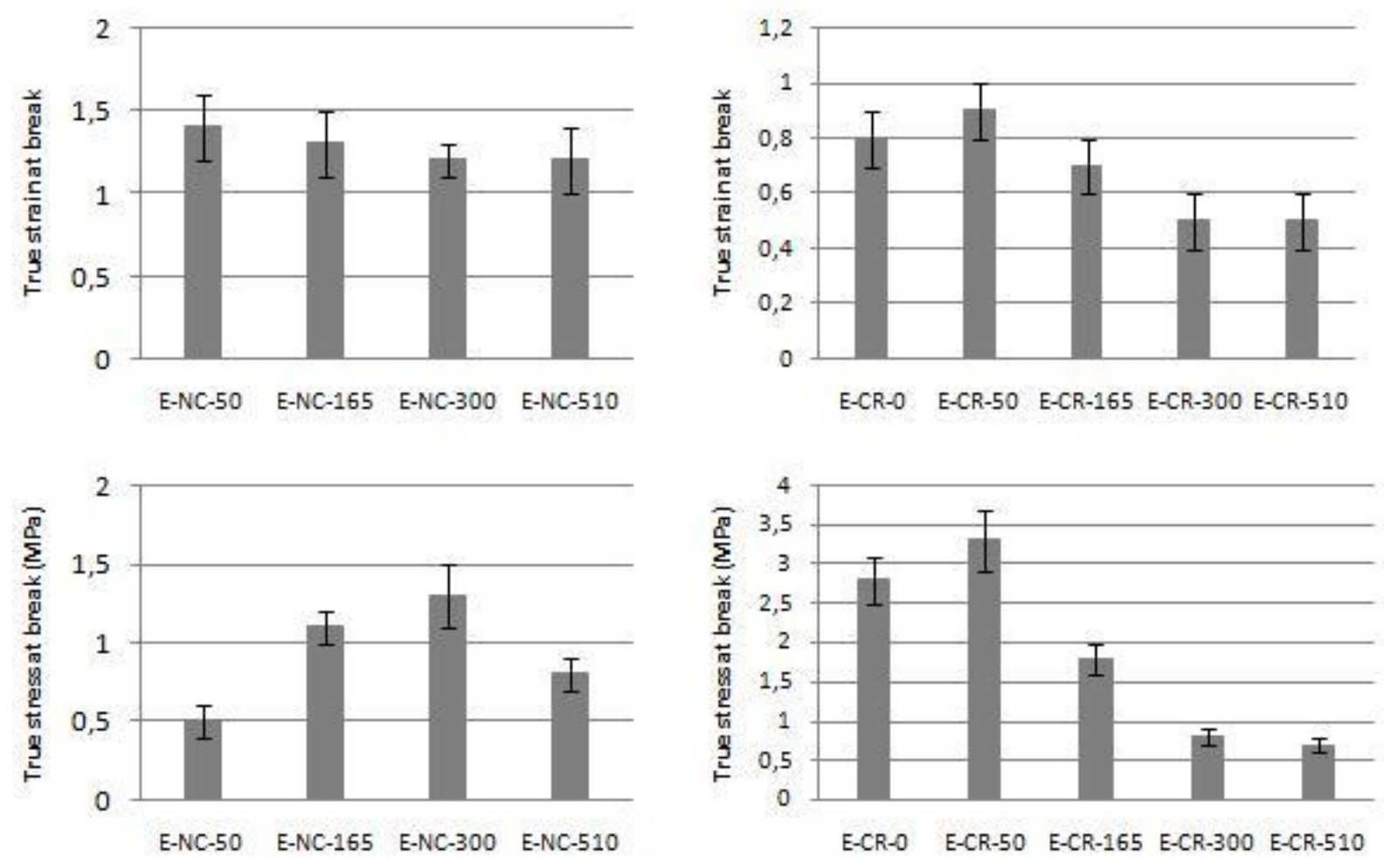

Figure 8: Average stresses and strains at break for tensile tests at $80^{\circ} \mathrm{C}$ of $E-N C$ and of $E-C R$

Concerning E-CR samples, the evolution of the stress level at a given strain with the irradiation dose is also in agreement with the previous results. However, except with the E$\mathrm{CR}$ aged at 50kGy, ageing under irradiation leads to a decrease in the elongation at break and to the disappearance of a strain hardening phenomenon prior to rupture. In figure 9 we compare E-CR2min, E-CR3min, E-NC-165, E-CR-0, 300, and 510. As reported in table 2, though their moduli are comparable, E-CR2min, E-CR3min and E-CR-300 exhibit very different rupture behaviors, the latter having much smaller stress and strain at break. E-CR510 and E-NC-165 also have roughly the same modulus, but the true strains at break are different (with a 2.5 ratio). It seems quite reasonable to conclude that there is no direct correlation between modulus and rupture behavior. The swelling ratios of the same samples 
are also reported in the same table. They also demonstrate an absence of correlation between $\mathrm{Q}$ and the rupture behavior.

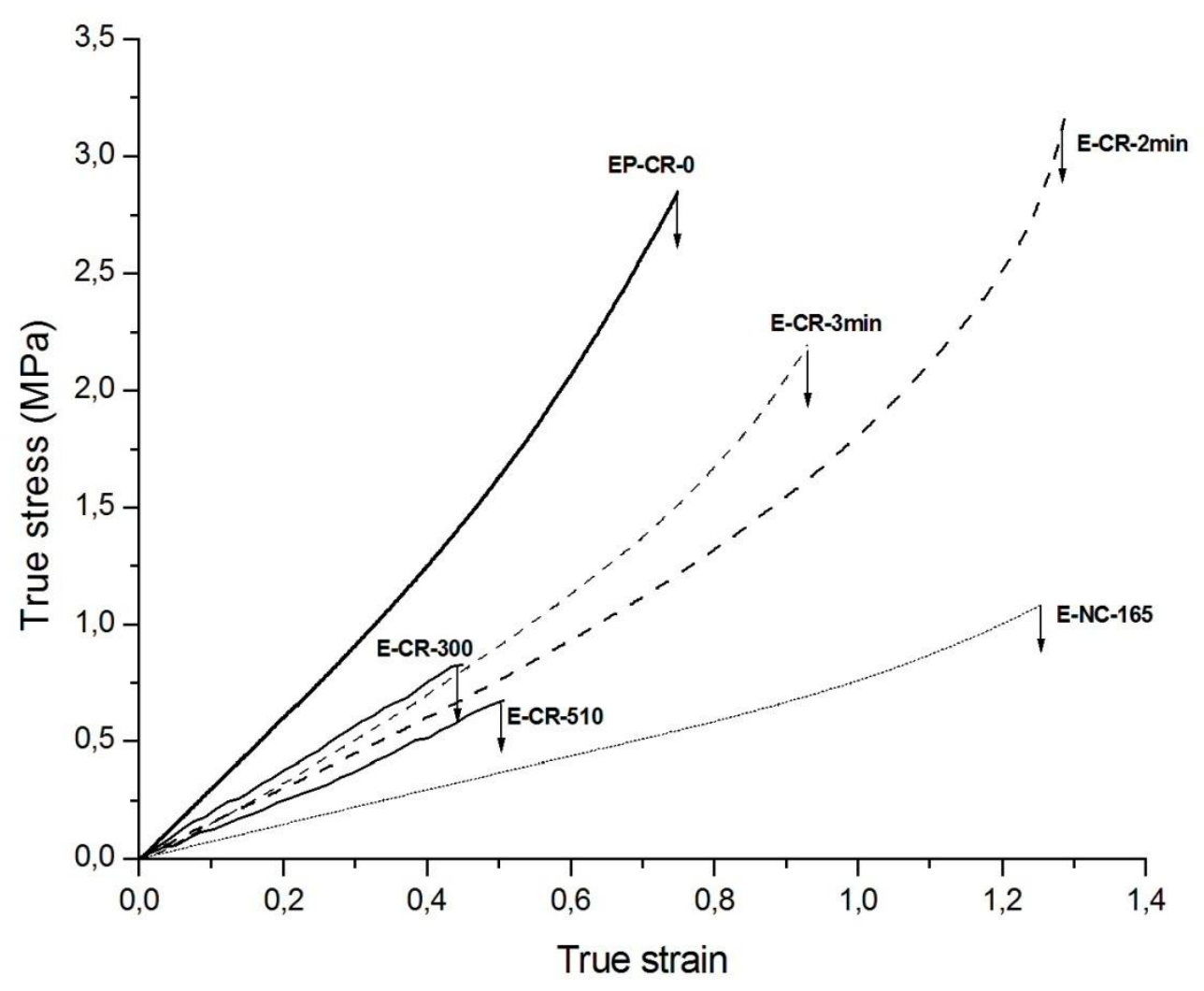

Figure 9: Large deformation behaviors at $80^{\circ} \mathrm{C}$ of irradiated elastomers and of crosslinked rubbers with different curing time

In summary, the mechanical measurements at small deformations are in agreement with the swelling measurements, but the evolution of the rupture behavior cannot be explained by a decrease in active chain concentration alone. During ageing the degradation exhibits induced defects such as dangling chains, free chains, and network heterogeneities that may in fact be primarily responsible for the rupture behavior observed. Studies of Mark et al. [11,12] suggest that a large proportion of short chains leads to a brittle behavior. This stresses the need for better characterization of network heterogeneities. 


\begin{tabular}{|c|c|c|c|c|c|}
\hline $\begin{array}{c}\text { Sample } \\
\text { name }\end{array}$ & $\begin{array}{c}\text { Soluble } \\
\text { Fraction } \mathrm{F}_{5} \\
(\%)\end{array}$ & $\begin{array}{c}\text { Elastic } \\
\text { modulus at } \\
80^{\circ} \mathrm{C}(\mathrm{MPa})\end{array}$ & $\begin{array}{c}\text { Swelling } \\
\text { ratio Q }\end{array}$ & $\begin{array}{c}\text { Strain at } \\
\text { break }\end{array}$ & $\begin{array}{c}\text { Stress at } \\
\text { break } \\
(\mathrm{MPa})\end{array}$ \\
\hline E-CR-0 & 0 & $2.9 \pm 0.3$ & 3.7 & $0.8 \pm 0.1$ & $2.8 \pm 0.3$ \\
\hline E-CR-300 & 8.8 & $2.1 \pm 0.2$ & 4.8 & $0.5 \pm 0.1$ & $0.8 \pm 0.1$ \\
\hline E-CR-510 & 20.6 & $1.2 \pm 0.1$ & 6.2 & $0.5 \pm 0.1$ & $0.7 \pm 0.1$ \\
\hline E-NC-165 & 27.8 & $1.8 \pm 0.2$ & 10.8 & $1.3 \pm 0.2$ & $1.1 \pm 0.1$ \\
\hline E-CR-3min & 0 & $1.5 \pm 0.2$ & 5 & $0.7 \pm 0.1$ & $2.7 \pm 0.4$ \\
\hline E-CR-2min & 0 & $0.8 \pm 0.1$ & 5.7 & $1.1 \pm 0.1$ & $3.4 \pm 0.5$ \\
\hline
\end{tabular}

Table 2: Average stresses and strains at break of materials presented in figure 7 compared to their soluble fraction $F_{s}$ and their swelling ratio $Q$

\subsection{Network heterogeneity}

The network heterogeneity has been characterized by thermoporosimetry. Figure 10 presents the DSC curves of the swollen (in cyclohexane) irradiated E-CR, E-NC-165, E-CR-2min and E-CR-3min. The melting peaks are shifted towards higher temperatures with increasing radiation dose, indicating that the size of solvent pockets increases. With E-NC-165, even though it has the highest modulus of the irradiated E-NC series, the melting peak overlaps the free solvent peak, meaning that the solvent pockets are very large. This is in alignment with the previous results showing that E-NC irradiated is only very slightly cross-linked. Thus for this kind of material, the distribution of pockets sizes cannot be accurately evaluated. 

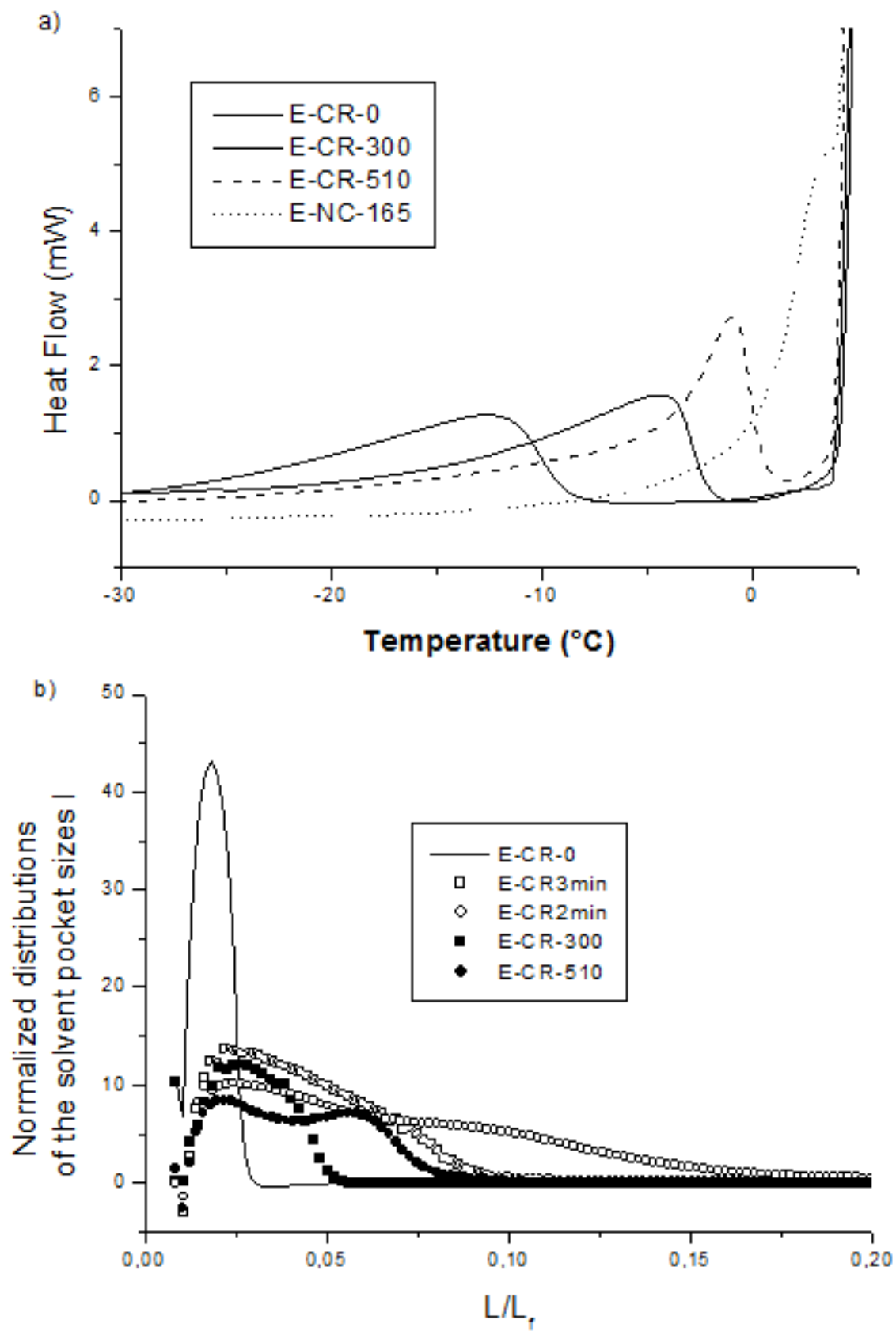

Figure 10: a) DSC-Analysis of the E-CR-0, 300, 510 and E-NC-165 swelled in cyclohexane, b) Normalized distributions of the solvent pocket sizes I for different materials

The distributions of pocket sizes are extracted from the following treatments. The GibbsThomson equation describes the melting temperature of liquids confined into a porous medium $\mathrm{T}_{\mathrm{m}}[26]$ as follows: 


$$
T_{m}{ }^{0}-T_{m}=\frac{2 \sigma_{S L} T_{m}{ }^{0}}{L \Delta H_{f}}
$$

where $\sigma_{\mathrm{SL}}$ is the solid-liquid interface energy, $\Delta \mathrm{H}_{\mathrm{f}}$ is the bulk heat fusion $(6.3 \mathrm{~J} / \mathrm{g}), \mathrm{L}$ refers to the crystal size (here the solvent pocket size), and $\mathrm{T}_{\mathrm{m}}{ }^{0}$ is the melting temperature for the bulk material (i.e. solvent), $0^{\circ} \mathrm{C}$.

The distributions can be obtained by differentiating the equation (13). As $\sigma_{\mathrm{SL}}$ is unknown, we have expressed these distributions as function of a parameter $\mathrm{L}_{\mathrm{f}} . \mathrm{L}_{\mathrm{f}}$ is the highest pocket size measured in all the samples. This pocket size corresponds to a melting temperature $\mathrm{T}_{\mathrm{f}} \mathrm{M}$ is the sample weight.

$$
\begin{gathered}
\frac{d M}{d L}=A \frac{\frac{d H}{d T}\left(T_{m}{ }^{0}-T\right)^{2}}{L_{f}} \\
\text { With } A=\frac{1}{\Delta H_{f}\left(T_{m}{ }^{0}-T_{f}\right)}
\end{gathered}
$$

The results from the analysis are presented in figure $10 \mathrm{~b}$ ). The normalized distribution of the solvent pocket sizes I is calculated using the following relation:

$$
I=\frac{1}{A M} \frac{d M}{d L}
$$

The average size of the solvent pockets as well as their size distribution increases with the radiation dose. Two peaks are visible for the most irradiated material. E-CR3min and ECR2min have a wide distribution of solvent pocket sizes. Thus, an increasing curing time leads to an increase in the cross-link density and a narrower distribution of the chain length in between cross-links. E-CR2min presents the largest distribution. E-CR3min and E-CR-510 have comparable distributions, even though their mechanical properties are very different. Thus, sole consideration of distribution alone is insufficient to explain rupture behavior. It is 
noteworthy that E-CR-510 and E-CR3min have a very different sol fraction, $20 \%$ and $0 \%$ respectively. The sol fraction can be formed of short portions of chains, but also of chain agglomerates which are mechanically inactive. This might very well be the reason behind the difference in mechanical properties of those materials. In order to have more insights on this aspect, a modeling approach of the elastomers architecture is necessary.

\subsection{Simulation}

A model was developed to describe the degradation kinetic of the studied elastomer networks. Similarly to Termonia's work $[16,17]$, this network can be modeled by way of nodes and links, where tetrafunctional nodes describe the elastomer cross-links, and the links of polymer chain between those nodes. Each link is defined by its ending nodes and its length, i.e. the number of constitutive units, with a unit being assimilated into a monomer. To avoid border effects, periodicity of the network is implemented: The nodes of one edge are linked to the nodes of the opposite edge (see figure 11). A scission reaction corresponds to the statistically random breakage of one unit in the network, meaning that the more probable breakage of the long chains can be accounted for. (Note that the breakage is applied to the chain units and not to the nodes.) In parallel, a calculation is performed to calculate the average length of the dangling chains. This calculation keeps the memory of the length of broken chains so that they can be submitted to successive breakages. This enables the calculation of the part of the sol fraction which is due to successive breakages of a link. The second part of the sol fraction is the fraction of the isolated link agglomerates that are not linked to the polymer network. Moreover, the polymer network resulting from the degradation can be seen as a network backbone grafted by a more or less complex branched structure. This network backbone is 
numerically obtained by iterative elimination of all chains having a free end. This process enables the calculation of the molar mass distribution of the branches either linked or unlinked to the network. The molar mass distribution between active nodes of the chain constituting the "clean" network backbone is then deduced by considering that the chains are part of the same chain if they are linked to each other by a bifunctional node. In other words, the dangling chains linked to this node are ignored in the calculation of the average molar mass of the active network.

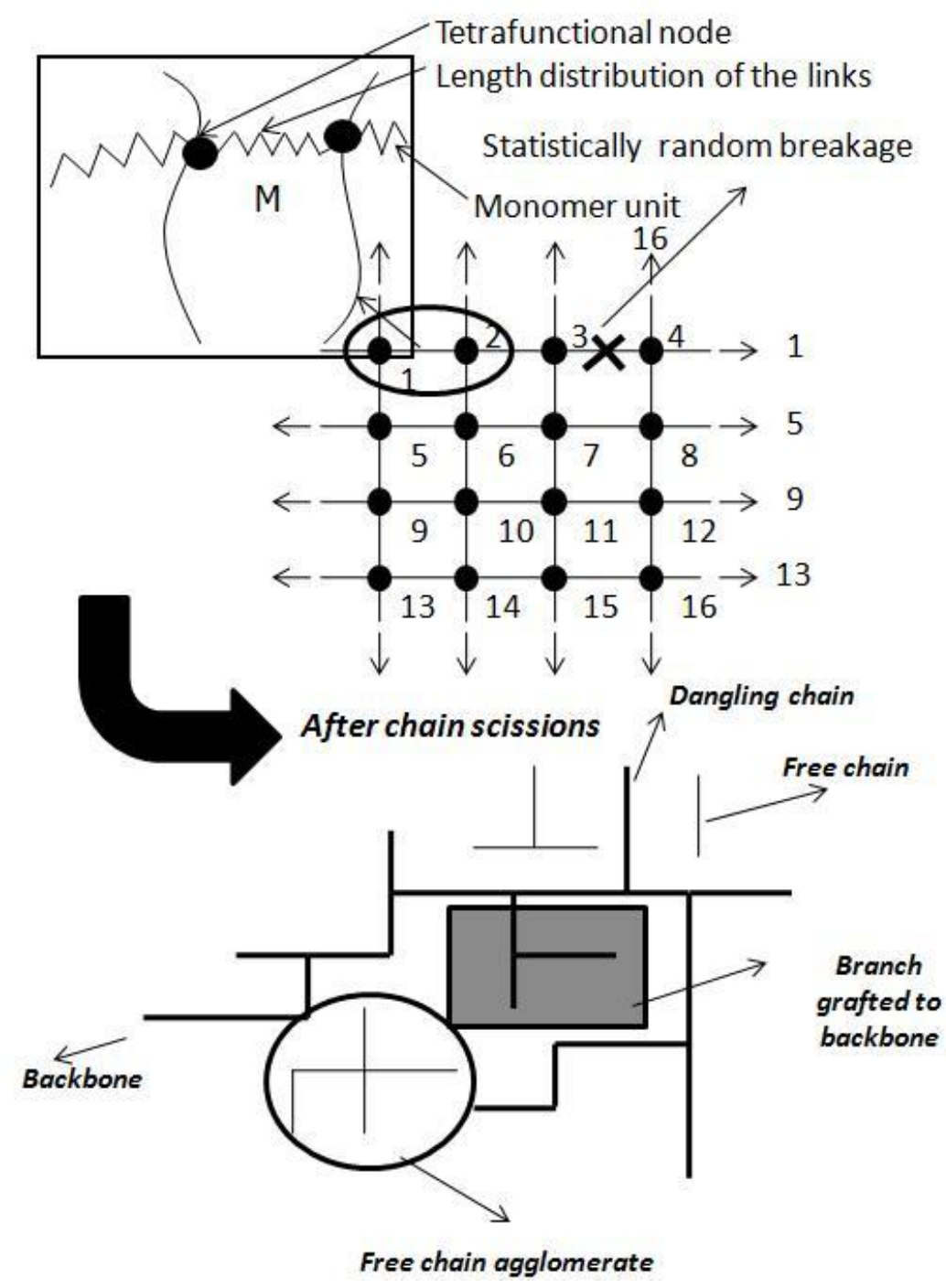

Figure 11: Scheme of model network 
The model parameters are the number of nodes, the molar distribution of the links (i.e. the distribution of their number of units), and the number of scissions. Calculations were performed with 4900 nodes (9800 links). In order to check and improve the statistic, six simulations were perfromed and the results presented are the average of these. Moreover, it has been checked that the use of only 625 nodes gives the same mean estimations, but with a larger standard deviation.

The presented model does not include any cross-linking process. The latter can be considered by increasing the initial cross-link density of the network submitted to the degradation kinetic. As shown previously, E-CR degradation primarily consists of chain scissions, except during the first stage of degradation, where slight cross-linking occurs. Therefore, one can consider the degradation kinetic of this material as the chain scission process of an E-CR initially slightly more cross-linked than the real initial material. From the previous extrapolation at 0kGy of the modulus (cf. figure 3), we consider an initial average chain length between crosslinks $\mathrm{N}_{\mathrm{c}}$ of 66 units. So this model accounts for a total of 646800 units $(66$ x 9800).

Additionally, the calculation needs the knowledge of the distribution of the number of units between cross-links in the initial material. The cross-linking process is initiated by peroxide. The latter is assumed to be randomly distributed in the unlinked EPDM. This means that the cross-linking can be assumed to occur between chains with the conformational state following the Gaussian statistic. Thus, the probability $P(r)$ for the distance between two cross-links having a distance $r$ will obey:

$$
P(r)=\frac{4 \pi r^{2}}{2 / 3 \pi\left\langle r^{2}\right\rangle^{3 / 2}} \exp \left(\frac{-3 r^{2}}{2\left\langle r^{2}\right\rangle}\right)
$$

with $\sqrt{\left\langle r^{2}\right\rangle}$ being the average distance between two cross-links given by: 


$$
\left\langle r^{2}\right\rangle=C_{E P D M} N_{c} b^{2}
$$

where $\mathrm{C}_{\mathrm{EPDM}}\left(\mathrm{C}_{\mathrm{EPDM}}=6.4\right)$ is the EPDM characteristic ratio, which in turn is an average value of the characteristic ratio of the polyethylene and the polypropylene $\left(\mathrm{C}_{\mathrm{PE}}=6.8\right.$ and $\mathrm{C}_{\mathrm{PP}}=5.5$ [30]). $b$ is the length of the monomer unit of EPDM, which in this case is the same as polyethylene: $b=0.308 \mathrm{~nm}$. In our case, $R_{c}$ is determined to be $13 \mathrm{~nm}$.

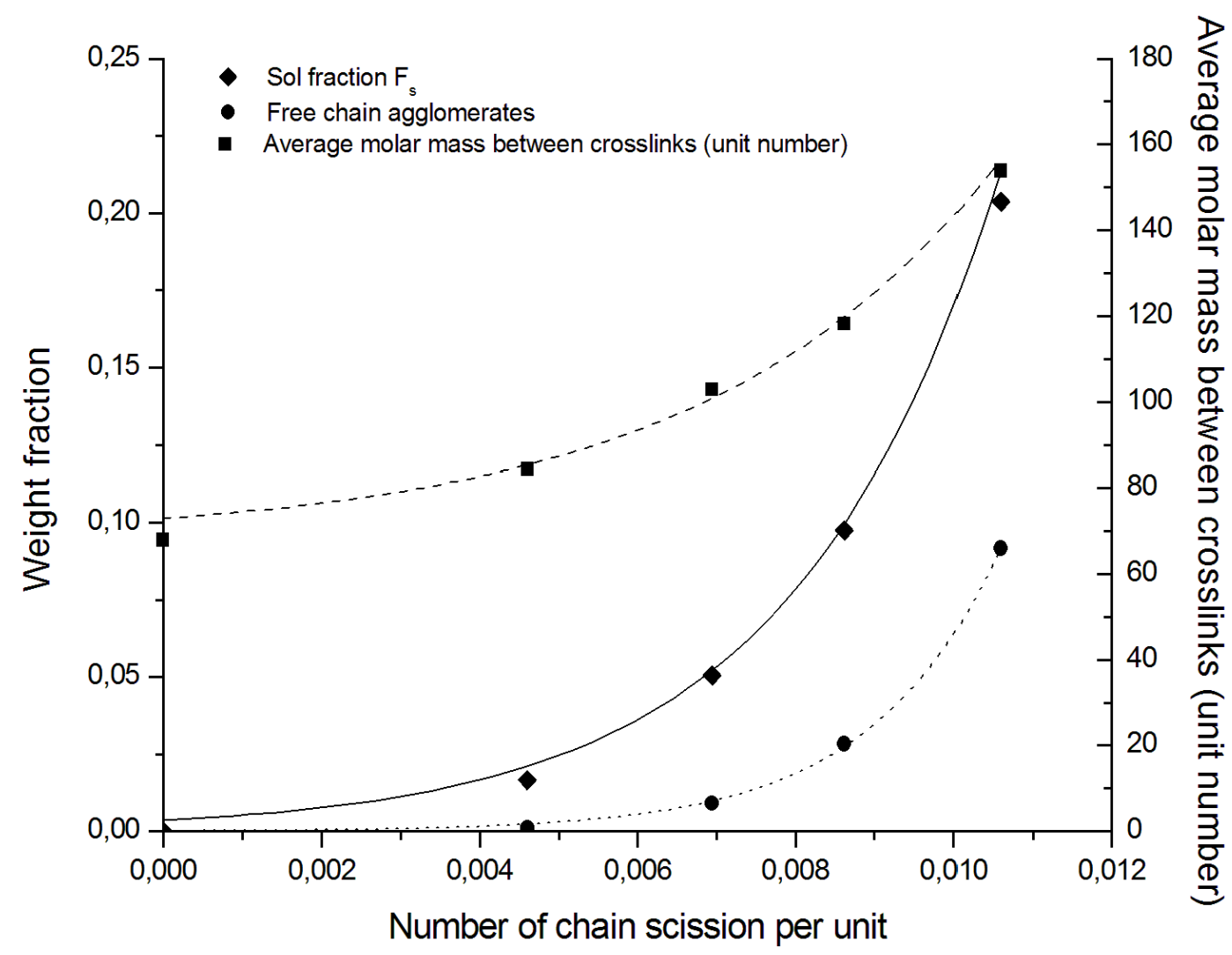

Figure 12: Calculated total sol fraction, free chain agglomerate fraction and average molar mass between cross-links as a function of the number chain scission per unit (calculation performed with an initial average length of active chains of 66 units)

Figure 12 presents the calculated evolution of the total sol fraction, and of the sol fraction made of chains containing at least two nodes and considered to be "free chain agglomerates", 
versus the number of scissions per the initial total number of units $\mathrm{N}_{\mathrm{s}}$. As we expect, the calculation indicates that the sol fraction at the beginning of the degradation process is mainly comprised of chain portions coming from dangling chains. As the number of scissions increases, free chain agglomerates rapidly become significant in the sol fraction: for $20 \%$ of soluble fraction, $9.2 \%$ is comprised of free chain agglomerates.

The calculations also predict the molar mass, and the number of free chain agglomerates and branches (belonging to the backbone) (cf. Figure 13) [23]. The scissions lead to a rapid increase in the number of branches followed by a stabilization for a number of chain scissions per unit around $10^{-2}$. At this level of damage, a large number of branches become separated from the network backbone and end up as free chain agglomerates. However, both types of agglomerates show an increase in size.

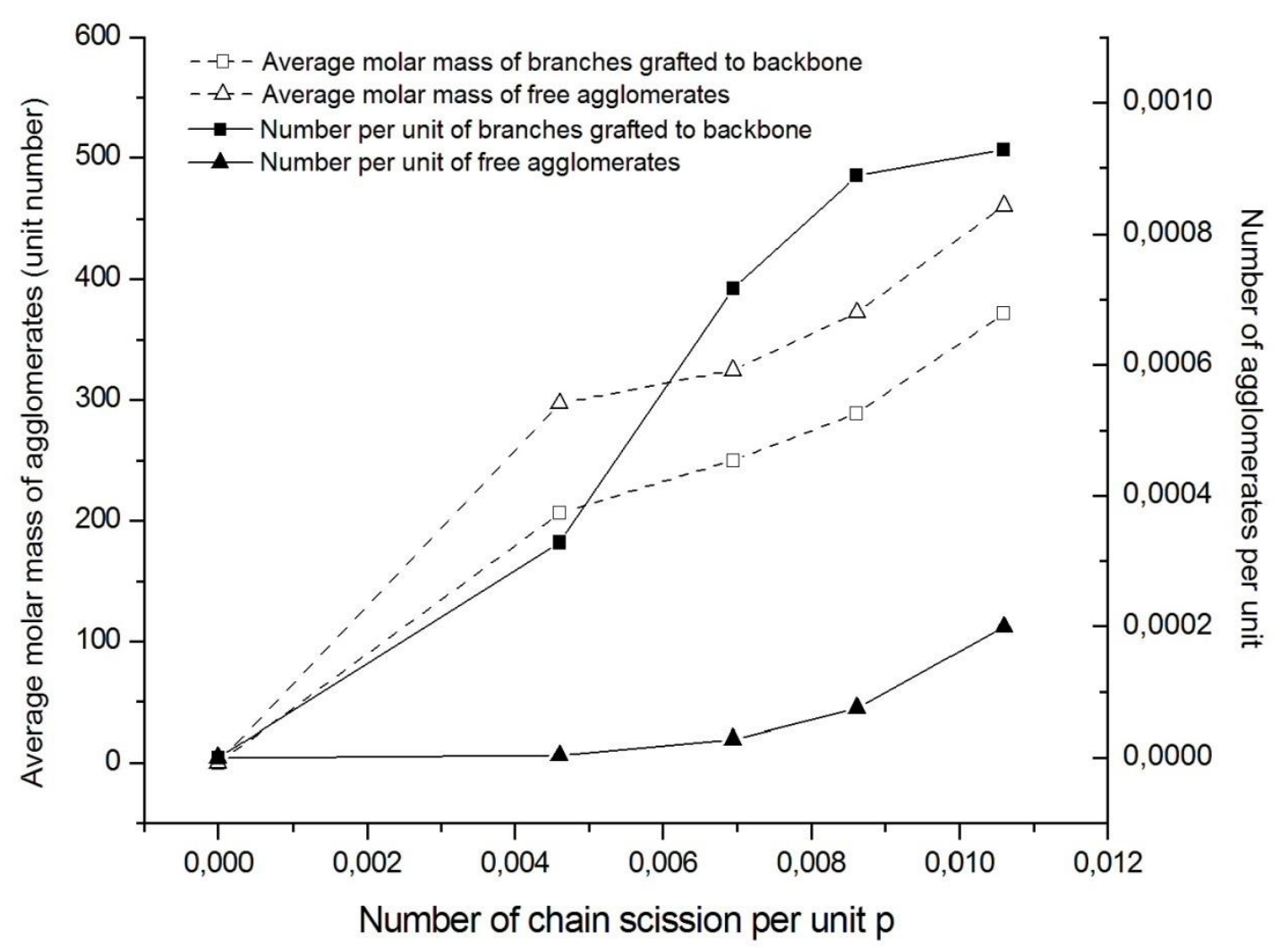


Figure 13: Size and number per unit of the free agglomerates and of branches grafted to

\section{backbone as a function of the number of chain scission per unit}

$\mathrm{N}_{\mathrm{s}}$ obtained from simulation at a given sol fraction can be compared to the experimental results from the same sol fraction required to extract an equivalent radiation dose. Figure 5 shows a non-linear relationship at the beginning of the cross-linking process. Conversely, a linear relationship is evidenced above $50 \mathrm{kGy}$. The deduced slope, equal to $1.2 \times 10^{-8}$ scission per unit per gray enables to us to estimate a chain scission yield. It is found a $\mathrm{G}_{\text {s-sim }}$ equals $3.9 \times 10^{-7} \mathrm{~mol} / \mathrm{J}$. This value is very close to that deduced from the Charlesby's model. Thus, this numerical model is roughly equivalent to the Charlesby's one for radiation doses above $50 \mathrm{kGy}$. The very high scission value needed at the beginning of the simulated degradation process in order to obtain the correct sol fraction value is due to the fact that the initial simulated network does not contain any dangling chains, in contrast to Charlesby's approach, which implicitly assumes their presence. Thus, the formation of sol fraction from such a network needs first the scission of chains, prior to the formation of soluble chains arising from the created dangling chains. Once such a process has been taken into account by a large initial scission kinetic, it can be considered, for sufficiently high dose (above $50 \mathrm{kGy}$ ), that the network characteristics simulated by our approach are roughly similar to those of the network modeled by Charlesby's approach.

From the calculated average molar mass $\mathrm{L}_{\mathrm{av}}$ (expressed in unit number) of the network "backbone", an average network density can be deduced, and ultimately the modulus of the calculated network (using the relation (12)) [23]:

$$
G_{\text {sim }}=\frac{\rho R T\left(F_{\text {Backbone }}\right)^{1 / 3}}{w L_{a v}}
$$


$\mathrm{F}_{\text {Backbone }}$ is the fraction of active chain in the gel. This means that we assume here that the dangling chains of the backbone are considered to form part of the soluble chains.

Figure 2 presents the modulus $\mathrm{G}_{\text {sim }}$ deduced from the simulation as a function of the radiation dose. As seen on the same figure, the simulated results correctly reproduce the modulus decrease. Note that there is an underestimation of around $20 \%$ between the calculated result and the experimental data in the dose range [50 kGy- $400 \mathrm{kGy}$ ]. This can be easily explained by the uncertainty in the initial cross-link density of the material. Actually, this value is probably underestimated since it is calculated with the assumption of no dangling chains; the real material necessarily contains these dangling chains. Whatever the radiation dose, making the assumption that the material at doses greater than or equal to $50 \mathrm{kG}$ is correctly simulated, the calculation indicates that around $20 \%$ of the gel is comprised of dangling chains. It is reasonable to consider that their content in the non-irradiated material is of the same order. As discussed in several studies [10,31,32], a presence of dangling chains in a network results in a reduction of the active chain concentration. Actually their effect is complex: Dusek et al. [32] or Mark et al. [10] have shown that they act as a kind of diluent which is however less mobile than a low-molar-weight compound or sol. Therefore, the cross-link density, and thus the average number of units in between cross-links of non-irradiated material used in the calculation (deduced from the modulus extrapolation at $0 \mathrm{kGy}$ with an assumption of $0 \%$ sol fraction) is likely underestimated by $10-20 \%$. Such a correction would lead to a very good model of the modulus evolution of E-CR. 


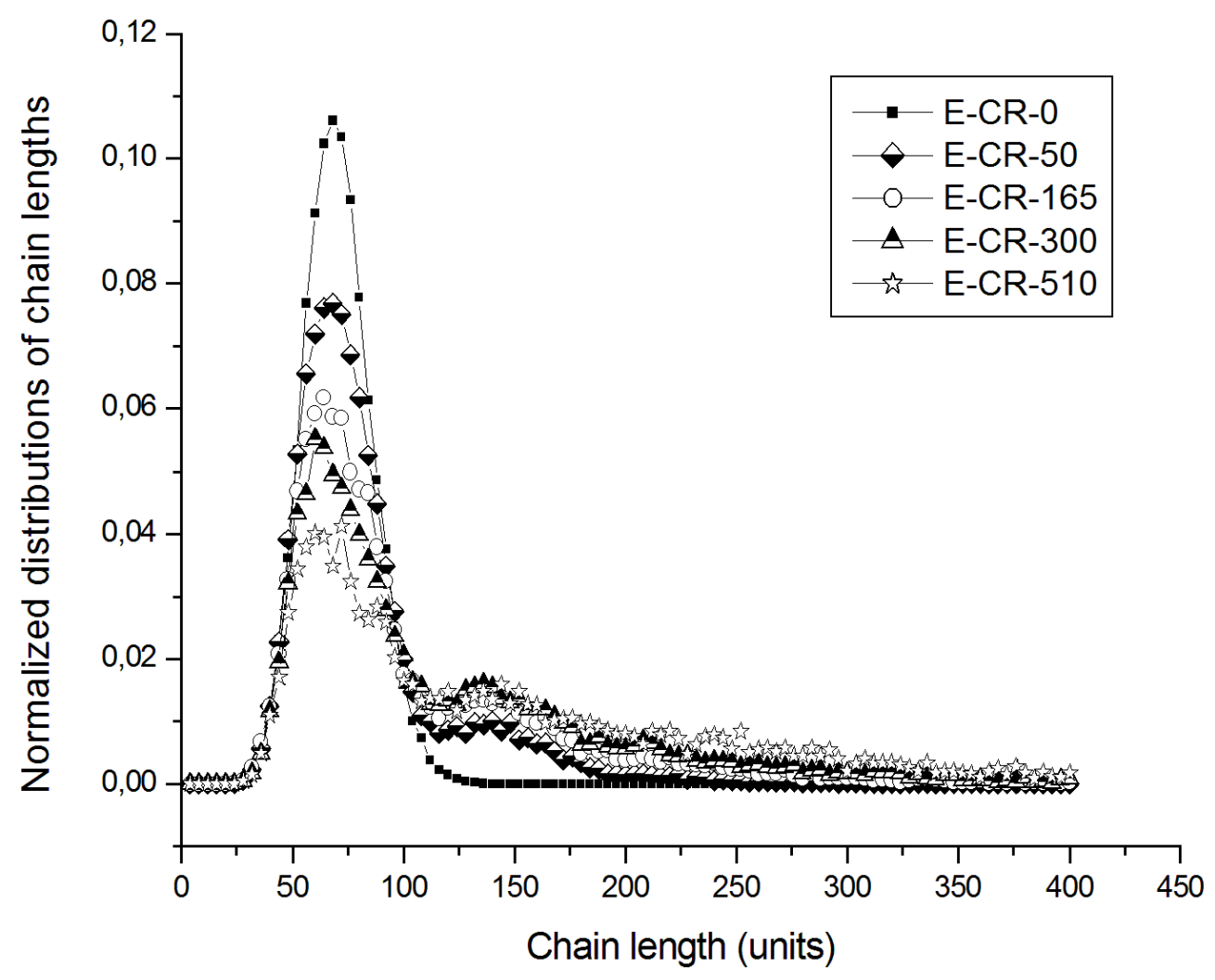

Figure 14: Normalized distribution of chain lengths calculated for E-CR as a function of irradiation dose (for a volume of 689000 units, results average of six calculation runs)

Figure 14 shows the simulation of the distribution of the molar mass between active crosslinks in the E-CR degraded network for the different radiation doses. As expected, chain scissions lead to the appearance of supplementary peaks centered on values equal to multiples of the initial average length of the chain in the E-CR network. Thus this simplified model correctly accounts for the trends observed in thermoporosimetry: an increase in the average molar mass between cross-links of the network, an increase in their distribution width towards the larger length, and the appearance of a modulation of the distribution. 


\section{Discussion}

The decrease in the average cross-link density should increase the strain at break of the E-CR. This is experimentally observed in the case of less cross-linked E-CR2min and E-CR3min. Indeed, compared to virgin E-CR, these samples have a larger strain at break correlated to their average cross-link density deduced from modulus measurement. Conversely, for irradiated E-CR, the average cross-link density decreases while the strain and stress at break decrease. Therefore the average cross-link density is not the only pertinent parameter required to predict rupture behavior: One must also consider the architecture of the network. The decrease in homogeneity of the network can be evaluated from the experimental results of thermoporosimetry, which are qualitatively in agreement with the calculated distribution of the average molar mass between active nodes. However it is noteworthy that E-CR3min and E-CR-300 have similar elastic modulus at $80^{\circ} \mathrm{C}$ and the same results in thermoporosimetry (i.e. a similar distribution of elastic network heterogeneity), whereas their rupture behavior is very different. The main difference between these materials is the sol fraction. The calculations have shown that this sol fraction contains more and more free chain agglomerates as radiation dose increases. Simultaneously, degradation leads to creation of larger and larger branches grafted to the network backbone. Thus the network architecture becomes very irregular. This means that the network contains an increasing number of weakened zones, which can lead to crack initiation. This phenomenon is concomitant with an increase in the average length of the active chains of the network. However, given the distributed character of these chain lengths, the elongation at break is likely controlled by the shortest chains, percolating through the whole sample. Thermoporosimetry and calculations clearly show the modification of the initial distribution into a multimodal one, in which the fundamental mode corresponds to the initial population. At the start of the degradation process, this population controls the elongation at break, while obviously at elevated radiation doses, the memory of 
this population vanishes while longer populations lead to an increase in elongation at break. By appreciating these mechanisms, one can propose an underlying cause for the rupture behavior of all the samples.

The elongation and stress at break of E-CR first decrease with radiation doses, because of the more numerous weak cross-links in the network. Up to $300 \mathrm{kGy}$, this effect is insufficiently counterbalanced by the increase in the average chain length in the network, since the network is still mainly constituted of the initial population of chains. On the other hand, the slight increase in the strain at break observed in the case of the most irradiated sample (E-CR-510) might be due to the degradation being severe enough to completely destroy the "percolation" of these initial chains.

In the case of E-NC, the evolution of the rupture behavior with radiation dose is the result of the concomitant cross-linking and bond-breaking processes. Unfortunately, the same simulation approach cannot be similarly applied to E-NC due to the important cross-linking process occurring in the same time as the chain scission one. However, the irradiated materials can be envisioned as an initial network whose the stress and strain at break is controlled by an initial average length, one which decreases with the radiation dose, submitted to a degradation processes which creates large free agglomerates. Thus, the E-NC-50 is a loose network, with an expected large strain at break, but with a large sol fraction, having numerous weakened zones, which decrease the strain at break. Then further irradiation leads to more cross-links in the initial network, which would be expected to decrease the strain at break, although kept in check by the chain scissions. Thus, at higher doses, the irradiated material can be seen as an initially cross-linked network with an average mass between crosslinks larger than that of the E-CR-0 network. This should lead to a strain at break much larger 
than that of this material. But the presence of sol fraction, i.e. of weakened links, leads to a decrease in strain at break to a smaller value, which is still above E-NC-510.

\section{Conclusions}

Different EPDM elastomers with different cross-link densities were processed in order to evaluate the influence of gamma irradiation on their properties. Depending on the initial cross-link density of sample, irradiation can lead to supplementary cross-linking of polymer chains. This mechanism is important for initial unlinked sample. For samples with initial high cross-link density, this mechanism also occurs at the lowest radiation doses and becomes negligible at high doses, where chain scissions mainly occur. These different phenomena are correctly accounted for by the Charlesby-Pinner modeling approach for doses equal or above 50kGy. This model indicates that, within the experimental conditions of our study, the chain scission mechanism involved in the degradation of the cross-linked EPDM is proportional to the radiation dose. In the case of the initially unlinked EDPM, the experimental results at high radiation doses suggests that the scission mechanism follow the same kinetic, i.e. a proportionality between scission and radiation dose. Assuming such a scission kinetic, a cross-linking kinetic can be estimated, and is found to be not proportional to the radiation dose. This mechanism saturates when the cross-linking density is close to that estimated for non-irradiated cross-linked EPDM. This suggests that the cross-linking mechanism should be very similar to that induced by either irradiation or by chemical (peroxide) curing.

Concerning the initially cross-linked material, the consequences of the chain scissions are a decrease in the modulus of elasticity, but also in the strain at break. This behavior is opposite to that expected for materials with increasing average chain length between cross-links. This 
surprising phenomenon is attributed to the presence of defects in network. Thermoporosimetry measurements were performed to characterize these defects, in particular the distribution of the average molar mass between cross-links. They show an increase in the distribution towards longer chains with increasing radiation dose, and for the highest radiation doses studied, a multimodal distribution. However, the experimental distributions found in the case of virgin networks with low cross-link density is much larger than that obtained with the most irradiated material, whereas their strains at break are more elevated than that observed for the aged sample. Thus it seems that the type of heterogeneity evidenced by such measurement cannot fully explain the evolution of the rupture behavior under ageing.

To produce new insights, a model has been developed enabling simulation of the chain scission mechanism of an elastomer network. It successfully enables prediction of the evolution of the elastic modulus of the material, based on an estimation of average chain length between active cross-links. The appearance of the multimodality of the average molar mass between cross-link distributions for high radiation doses is also predicted. This model furthermore predicts the proportion of free chains, of free chain agglomerates and of branches linked to the network backbone. From this information on the evolution of the network architecture, two key parameters have been identified for the rupture behavior and its evolution with ageing. The first is the average molar mass between cross-links, which controls the rupture of a network in the absence of defects. The second is the proportion of weakened zones comprised of large free agglomerates, and large branched chains in the mechanically active network backbone, which degrade the rupture property. 


\section{Acknowledgements}

It is a pleasure to acknowledge the joint research program "COPOLA" between EDF,

NEXANS France, LABORELEC, CEA, INRA and CNRS. The authors also thank J.C. MAJESTE for GPC analyses, and Julian de Marchi for corrections of the english.

\section{References}

1. RIVATON A, CAMBON S, GARDETTE JL. Nuclear Instruments and Methods in Physics Research B 2005; 227: 343-356

2. RIVATON A, CAMBON S, GARDETTE JL. Nuclear Instruments and Methods in Physics Research B 2005; 227: 357-368

3. CELETTE N, STEVENSON I, DAVENAS J, DAVID L, VIGIER G. Nuclear Instruments and Methods in Physics Research B 2001; 185: 305-310

4. CELETTE N, STEVENSON I, DAVID L, VIGIER G, SEYTRE G. Polymer International 2004; 53: 495-505

5. ASSINK RA, GILLEN KT, SANDERSON B. Polymer 2002; 43:1349-1355

6. CELINA M, GILLEN KT, WISE J, CLOUGH RL. Radiation Physics and Chemistry 1996; 48:613-626

7. ASSINK RA, CELINA M, GILLEN KT, CLOUGH RL, ALAM TM. Polymer Degradation and Stability 2001; 73:355-362

8. BATEJA SK. Journal of Applied Polymer Science 1983; 28:861-872

9. PlANES E, CHAZEAU L, VIGIER G, CHENAL JM, STUHLDREIER T. Submitted to Polymer 2009

10. ANDRADY AL, LLORENTE MA, SHARAF MA, RAHALKAR RR, MARK JE. Journal of Applied Polymer Science 1981; 26: 1829-1836

11. MARK JE, TANG MY. Journal of Polymer Science: Polymer Physics Edition 1984; 22: $1849-1855$

12. LLORENTE MA, ANDRADY AL, MARK JE. Journal of Polymer Science 1981; 19: 621-630

13. MADKOUR T, MARK JE. Polymer Bulletin 1993; 31: 615-621 
14. TERMONIA Y. Macromolecules 1989; 22:3633-3638

15. TERMONIA Y. Macromolecules 1990; 23:1481-1483

16. GREST GS, KREMER K. Macromolecules 1990; 23: 4994-5000

17. CHARLESBY A, PINNER SH. Proc. Roy. Soc. Lond. 1959; A249:367-386

18. CHARLESBY A. Proc. Roy. Soc. Lond. 1954 A222:542-557

19. ROTTACH DR, CURRO JG, GREST GS, THOMPSON AP. Macromolecules 2004; $37: 5468-5473$

20. ROTTACH DR, CURRO JG, BUDZIEN J, GREST GS, SVANEBORG C, EVERAERS R. Macromolecules 2006; 39:5521-5530

21. ROTTACH DR, CURRO JG, BUDZIEN J, GREST GS, SVANEBORG C, EVERAERS R. Macromolecules 2007; 40:131-139

22. VALLAT MF, RUCH F, DAVID MO. European Polymer Journal 2004; 40: 1575-1586

23. FLORY PJ, REHNER J. Journal of Chemical Physics, 1943; 11: 521-526

24. VALENTIN JL, CARRETO-GONZALEZ J, MORA-BARRANTES I, CHASSE W, SAALWACHTER K. Macromolecules 2007; 11: 4717-4729

25. HONIBALL D, HUSON MG, MCGILL WJ. Journal of Polymer Science: Part B: Polymer Physics 1988; 26: 2413 - 31

26. QIN Q, MC KENNA GB. Journal of Polymer Science: Part B: Polymer Physics 2006; 44: $3475-3486$

27. KHELIDJ N, COLIN X, AUDOUIN L, VERDU J, MONCHY-LEROY C, PRUNIER V. Polymer Degradation and Stability 2006; 91(7):1593-1597

28. DECKER C, MAYO FR, RICHARDSON H. Journal of Polymer Science: Polymer Chemistry Edition 1973; 11: 2879-2898

29. COLIN X, RICHAUD E, VERDU J, MONCHY-LEROY C. Conference IRAP 2008, Kinetic modelling of radiochemical ageing of ethylene-propylene copolymers Submitted to Radiation Physics and Chemistry

30. SPERLING LH. Introduction to physical polymer science - Second edition. Wiley interscience, 1992.

31. VILLAR MA, VALLES EM. Macromolecules 1996; 29: 4081-4089

32. DUSEK K, DUSKOVA-SMRCKOVA M, FEDDERLY JJ, LEE GF, LEE JD, HARTMANN B. Macromolecular Chemistry and Physics 2002; 203:1936-1948 